\title{
Arquitectura y cinematógrafo en la ciudad de Vigo: Palacios, Gutiérrez Soto, Francisco Castro y Pedro Alonso
}

\author{
Xose M. ${ }^{a}$ Ramón lglesias Veiga
}

Desde las primeras décadas del presente siglo, el cine permitió, por su carácter de espectáculo nuevo y sobre todo por ser la expresión de los tiempos modernos, la utilización de nuevos materiales y tipologias arquitectónicas que eran difíciles de incorporar a otro tipo de edificaciones, bien por su carácter oficial, bien por estar sujetas al condicionante del gusto estético del encargante particular. Algunas ciudades españolas incorporan tempranamente innovaciones de la arquitectura de vanguardia a sus salas de cine, como sucede en Madrid, donde destaca la actividad de Teodoro Anasagasti, uno de los primeros arquitectos españoles que advirtió el gran porvenir del hormigón armado, no sólo por sus virtudes constructivas, sino también por sus posibilidades expresivas ${ }^{~}$. Estas innovaciones están presentes en el Real Cinema (1922), donde, además de utilizar hormigón, realiza estudios de color e iluminación artificial, en el Monumento Cinema (1923), empleando una estructura completa de hormigón en una sala de gran aforo y en el cine Pavón (1923-1925) presentando un lenguaje plástico más avanzado y limpio, que prepara el camino a la actuación, en este de campo, de Gutiérrez Soto.

En la ciudad de Vigo, la incorporación de las nuevas tendencias arquitectónicas a las salas de cine se hace lentamente, no llegando a concretarse el nuevo lenguaje racionalista en un edificio dedicado a cinematógrafo hasta la conclusión de la Guerra Civil. Sin embargo, en la ciudad trabajarán arquitectos de reconocido prestigio, como es el caso de Antonio Palacios y de Gutièrrez Soto. Este último de actuación progresista

\footnotetext{
1 Véase: Garcia Morales, M." Victoria, "Teodoro Anasagasti", en Arquitectura madrileña de la primera mitad del siglo xx. Madrid, Ayuntamiento de Madrid, 1987, págs. 63-91.
} 
en las salas que proyecta en Madrid, pero contagiado por el carácter tradicional de la arquitectura viguesa en el proyecto que realiza para esta ciudad.

Vigo, es a principios de siglo, una ciudad en expansión que pasa de ser una reducida villa marinera en los inicios del siglo xIX, a convertirse en una ciudad moderna en este periodo, favorecida por la actividad de una burguesia relacionada con las actividades maritimas, entre las que destacará una pujante industria conservera. A pesar del fracaso de los sucesivos proyectos de ensanche planificado, de los que solamente se realiza una pequeña parte, la ciudad consolida una fuerte expansión hacia el este, a lo largo de las principales vías de comunicación. Serán éstas, unidas entre sí y convertidas en calles principales, las que reciban lo más significativo de la arquitectura de la ciudad, formando un rico conjunto patrimonial, que conserva, por encima de la incorporación de las diversas tendencias, un carácter propio, al utilizar en todo su conjunto el granito. La incorporación de este material llega incluso a las construcciones más modestas, creando una agradable sensación de solemne armonía, perdida en gran parte en la actualidad, debido a la lacra de la especulación ${ }^{2}$. Siguiendo el ritmo de la expansión de la ciudad, la burguesia viguesa va a demandar una arquitectura suntuosa y elegante que sea expresión de su posición. La ciudad pasa a tener un aire cosmopolita, con una arquitectura en la que se mantiene un eclecticismo decimonónico, en el que prevalece la influencia de la arquitectura francesa del Segundo Imperio. Junto a arquitectos titulados como Franco Montes, Benito Gómez Román, Felipe Quintana o el polaco, formado en Francia, Pazewicz, destaca la labor del maestro de obras Jenaro de la Fuente Dominguez, quien, por la gran cantidad de proyectos realizados y por su actividad como facultativo municipal, va a contribuir poderosamente al cambio de fisonomia de la ciudad. Al lado del eclecticismo academicista, aparece la influencia modernista, principalmente vienesa, presentándose de manera atenuada, recogiendo elementos estilisticos y sobre todo decorativos de la nueva tendencia y adaptándolos a edificios de carácter ecléctico, evitando las fuertes rupturas, dentro de una amanerada contención ${ }^{3}$. Los arquitectos que trabajan en la ciudad reflejarán, en momentos concretos de su obra, las tendencias en alza, para volver a un eclecticismo que evoluciona a formas

\footnotetext{
${ }^{2}$ Un completo trabajo sobre la arquitectura que paulatinamente fue perdiendo la ciudad, con una amplia parte gráfica, puede verse en:

- Garrido Rodriguez, Jaime, Vigo. La ciudad que se perdió, arquitectura desaparecida. Arquitectura no realizada. Pontevedra, Diputación Provincial, 1991

${ }^{3}$ Iglesias Rouco, Lena y Garrido Rodriguez, Jaime, Vigo. Arquitectura modernista, 19001920. Santiago de Compostela, COAG, 1980, págs. 20-44.
} 
más clasicistas. También estarán presentes en la ciudad los intentos regionalistas, fruto nostálgico y emotivo del movimiento galleguista y de la tendencia general de la arquitectura española a buscar una evolución desde propuestas especificamente hispanas. La ciudad, sigue por largo tiempo siendo deudora de un eclecticismo suntuoso y enfatizado con una rica ornamentación en piedra, que reserva siempre un espacio preferencial para el virtuoso trabajo del cantero ${ }^{4}$. Por esta razón las influencias de las corrientes de vangurdia tardan en incorporarse, siendo la arquitectura de las grandes salas de cine un ejemplo de esta situación. Destacará, desde los inicios de la década de los treinta la labor de Francisco Castro Represas, principal introductor en la ciudad de la corriente racionalista, a la que progresivamente, bajo su influencia, se irán sumando otros arquitectos de la ciudad. Será precisamente el Cinema Radio el que, dentro de la arquitectura de cines de la ciudad, presente claramente un lenguaje racionalista y funcional.

\section{LOS PRIMEROS CINEMATÓGRAFOS}

La implantación del cinematógrafo en la ciudad pasará, como sucede en otros puntos de España, por un primer período de exhibición ambulante ${ }^{5}$ que desembocaría, a partir de 1910, en la instalación de pequeños cines de barracón, que se ubican en la zona del ensanche de la ciudad, preferentemente en las proximidades de la Alameda, conservando todavía un cierto carácter de provisionalidad. Todos mantienen la caracteristica común, de presentar estructura de madera recubierta del mismo material o bien de tela y lona. De entre ellos destaca el salón Pinacho ${ }^{6}$, el pabellón Apolo ${ }^{7}$ y el Ideal Cinema ${ }^{8}$. Estos dos últimos serản remodelados por Jacobo Esténs y Jenaro de La Fuente Dominguez en 1916 y 1919, pero conservarán su estructura de madera. La decoración exterior es pobre o inexistente, a excepción del pabellón Guiñol que presentaba

\footnotetext{
${ }^{4}$ Conde Aldemira, Arturo y Santos Zas, Gabriel, "Análisis de la Arquitectura contemporánea viguesa", en Vigo en su Historia. Vigo, Caja de Ahorros, 1979, págs. 611-632.

Archivo Municipal de Vigo (AMV). Una completa documentación sobre estos primeros exhibidores puede consultarse en este archivo: Carpeta: URB-138, 157, 159, 160, 162, 165. 171 y 173

AMV. Inspección de Obras. Informe de Felipe Quintana sobre Salón Pinacho y Expediente sobre clausura y reapertura provisional del Gran cine Pinacho. Carpeta: URB-181.

AMV. Obras particulares. Carpeta: URB-173.

AMV. Proyecto de reforma del Ideal Cinema por Antonio Tourón en la calle de la Victoria y Pabio Morillo. Carpeta: URB-176.
} 
la novedad de cuidar ésta, apareciendo rasgos que se pueden relacionar con el modernismo ${ }^{9}$. La pujanza del nuevo espectáculo conlleva la transformación de locales que compartian la exhibición de peliculas con otros espectáculos, convirtiéndose en cinematógrafos, como sucede con el viejo teatro circo Tamberlick. Sin embargo, serán los cines Royalty y Odeón los que inicien el largo periodo de construcciones dedicadas exclusivamente a cinematógrafo. Ambos son proyectados, en 1916, por Álvarez Reyero, arquitecto que no trabaja habitualmente en la ciudad. El Royalty, con capacidad para 500 espectadores, presentaba una arquitectura ecléctica con fachadas recargadas de ornamentación, en las que está presente un cierto matiz arabizante, resaltado, en el proyecto original, por una decoración de azulejos que cubría la fachada principal, que definitivamente no fue llevada a cabo ${ }^{10}$. El Odeón ${ }^{11}$, con fachadas a tres calles y un aforo de 790 localidades, sigue la misma línea ecléctica del Royalty, estando también presente la ornamentación de base barroca. Alguno de estos cines tendrán una dilatada vida ${ }^{12}$. Sin embargo, la propia evolución del espectáculo hace que una arquitectura de mayor empaque se incorpore a las salas de cine en la ciudad con el cinematógrafo Rosalia de Castro.

\section{CINE ROSALIA DE CASTRO}

El cine Rosalia de Castro se inscribe dentro del complejo edificio del teatro Garcia Barbón. Su autor, Antonio Palacios Ramilo, nacido ${ }^{13}$ en el pueblo pontevedrés de O Porriño, el 8 de enero de 1874, es una de las figuras más importantes y controvertidas de la arquitectura española de las primeras décadas de siglo, con una fuerte actividad en la capital de España, ampliamente referenciada en los estudios dedicados a su obra ${ }^{14}$.

${ }^{9}$ AMV. Expediente formado a instancias de don Mario Gardeazabal. Carpeta: URB-173. Pabellón Guiñol. Carpeta: URB-138.

${ }^{10}$ AMV. Expediente Cine Royalty, en ángulo de las calles Marqués de Valladares y Velázquez Moreno de don Antonio Méndez Laserna. Carpeta: URB-174.

"AMV. Expediente a don Ángel Núñez Garcia para construir los pabellones destinados a espectáculos públicos. Carpeta: URB-174. Se conserva la memoria, faltan planos.

${ }^{12}$ Sobre estos primeros cines de la ciudad, véase: Garaido Rodriguez, J., Op. cit., págs. 16-47.

Archivo Parroquial de Santa María de O Porriño. Fe de Bautismo.

${ }^{14}$ En relación con el conjunto general de la obra de Palacios, véase:

- Gonzalez Amezoueta, A., "La Arquitectura de Antonio Palacios», en Revista Nacional de Arquitectura, Madrid, núm. 106, 1967.

- Pérez Rojas, Francisco Javier, "Palacios y Otamendi», en Arquitectura madrileña de 
Alcanzaria gran prestigio tras el triunfo, en unión de Otamendi, en el concurso de proyectos del Palacio de Comunicaciones (1904-1918), donde se deja llevar por la corriente que busca una arquitectura de carácter nacional, tendencia que estará siempre presente en su pensamiento, reconociéndose en varias ocasiones deudor de Aníbal Álvarez. Sin embargo, en su primera etapa creativa, mostrará cierto progresismo, tomando sus propias referencias de las corrientes internacionales, dentro de una manera propia de crear, en la que se dan cita las más diversas influencias, como sucede en el edificio de Correos, donde está presente el influjo de la Sezessión vienesa, la más atemperada de las modalidades del modernismo. En el Hospital de Maudes (1908-1916), una de las obras más definitorias de su estilo, aparece el gusto por la ruda expresividad de la piedra, que será llevada a su último grado en las últimas obras que proyecta en Galicia. En los edificios bancarios y comerciales, que se inician con el Banco Central (1910-1918), utiliza un lenguaje clasicista, ordenando verticalmente las fachadas con la colocación de columnas agigantadas con grandes miradores acristalados en los intercolumnios. A partir de la construcción del Circulo de Bellas Artes, su obra sufre una depuración de su virtuosa decoración, que sigue siendo clasicista, acentuándose los volúmenes compactos y los perfiles escalonados.

Para Galicia proyecta una copiosa obra, en gran parte no construida, permaneciendo en parte oscura y poco estudiada ${ }^{15}$. La primera obra realizada del conjunto de su producción es la Fuente del Cristo de O Porriño (1904), donde muestra elementos que serán caracteristicos de su obra: virtuosismo en la presentación de la piedra y utilización de la cerámica ${ }^{16}$. Por las mismas fechas realiza también en Porriño la escuela Fernández Arenal, absurdamente destruida en los años sesenta, en la que también incorporaba la cerámica y unos años después (h. 1910) la Botica Nova, para su hermano José. En 1909 proyecta la monumental Virgen de la Roca, en la que integra hierro, cerámica, granito y mármol, siendo en-

la primera mitad del siglo xx. Madrid, Ayuntamiento de Madrid, 1987, págs. 93-175.

- Gutiérrez Burón, Jesús, "Antonio Palacios Ramilo", en Cuadernos de arte de la Fundación Universitaria. Madrid, Fundación Universitaria Española, 1988.

- Alonso Pereira, José Ramón, Madrid, 1898-1931. De Corte a Metrópoli. Madrid, Comunidad de Madrid, 1985.

${ }^{15}$ Como trabajos monográficos sobre la obra de Palacios en Galicia, pueden consultarse:

- Beramendi, X., "Santiago de Compostela. Pabellón de Recreo: Antonio Palacios", Obradoiro. COAG, 1985, págs. 52-57.

- Lópz Gomez, Felipe Senén, "Antón Palacios e o Santuario da Veracruz de Carballiño", Obradoiro, COAG, núm. 6, 1980.

- Pereiro Alonso, J. L., Desarrollo y deterioro urbano de la ciudad de Vigo. Santiago, COAG, 1981

${ }^{16}$ Archivo Municipal de O Porriño. Acta notarial de la subasta. Año 1904. 
cargada la ejecución de la cara y manos de la Virgen, en este último material, al escultor Ángel Garcia. En el proyecto inicial estaba presente la idea de cubrir el manto y dengue de mosaicos, realizados en cuarzo blanco y cantos rodados de las playas cercanas, siendo definitivamente abandonada esta idea, quizá por el retraso considerable que sufrió la obra, debido a las grandes dificultades económicas que presentó su realización, caracteristica común de muchas de sus obras gallegas. También es norma común, la presencia de una idea simbólica, explicada detalladamente en cada memoria, que genera la concepción posterior del proyecto. En este caso relacionada con la primera noticia del descubrimiento de América tras la arribada de la Pinta a Baiona y con la Virgen como protectora de los hombres del mar.

En las primeras obras mantendrá un lenguaje clasicista, como sucede en el propio teatro Garcia Barbón o en la Banca Viñas (1942) de la ciudad de Vigo y en el Balneario de Mondariz, en pleno apogeo en estos años, donde, a partir de 1907 realiza el Pabellón de la Fuente, la Planta Embotelladora, el Hotel Sanatorio, atribuyéndosele también el edificio de «La Baranda". Progresivamente se acercará al campo regionalista, en una faceta poco estudiada, pero importante por la gran cantidad de proyectos realizados. Desde una posición no militante, sino cultural y a veces nostálgica y emotiva, se dejará contagiar por el movimiento galleguista, sumándose a la corriente que buscaba concretar un arte propio, que resaltara las peculiaridades gallegas. Su amistad con los pintores Sotomayor y Llorens y el escultor Asorey, representantes de esta tendencia, le lleva a participar en la organización de algunas de las exposiciones de arte gallego, realizadas en las principales ciudades de Galicia, con las que se intentaba promocionar esta tendencia, teniendo destacada participación en la celebrada en La Coruña en 1917 y en la primera celebrada en Madrid. En este sentido realizará una serie de colaboraciones en la prensa gallega ${ }^{17}$, en las que además de promocionar alguno de sus proyectos, en especial el Plan de Extensión y Reforma Interior de Vigo, realiza una labor de divulgación de los estilos históricos que se consideran más representativos de Galicia.

En esta parcela de su arquitectura, intentará enlazar con la tradición artística de Galicia y con los métodos tradicionales de construcción. En la elección del lenguaje marcará una diferenciación con las obras urbanas, ya que, la inspiración es ahora historicista, de base medieval, pero dentro de una visión particular y original, huyendo de la copia deliberada y de

\footnotetext{
17 Principalmente en los periódicos vigueses: Faro de Vigo, Galicia y El Pueblo Gallego (PG) y en la revista Vida Gallega.
} 
la cita, por lo que se apartan del vulgar pastiche en que cayeron muchos de los intentos regionalistas. Este matiz en la obra de Palacios se manifiesta por primera vez en el proyecto (1918), no construido, de la Encarnación de Celanova (Orense) que presenta un fuerte lenguaje historicista, diseñando un pórtico policromado, inspirado en la Puerta del Paraiso de la catedral de Orense. El ayuntamiento de O Porriño (1919-23), el proyecto de hospederia del Monte Santa Tegra, los chalés de Sileno y Celso Méndez en Playa América, la central eléctrica del Tambre, etc., presentan esta tendencia. Paulatinamente, el lenguaje historicista se va depurando y reelaborando, liberándose de la carga ornamental hasta llegar al fuerte expresionismo que presentan los templos de Panjón, Carballiño. Otros proyectos presentan las mismas caracteristicas: Templo de la Paz de Vigo, San Fausto de Chapela (Redondela), Monasterio de la Visitación de las Salesas Reales de Vigo, Parroquial de San Francisco de Santander y Santuario de la Gran Promesa de Valladolid. De todos ellos solamente se construirá este último y parte de las Salesas de Vigo. Estas obras de matiz regionalista, mantienen la coherencia del conjunto de la creación de Palacios, ya que en la obra madrileña también aparece una evolución y depuración ornamental, como se pone de manifiesto en el Hospital de Fuenfria de Cercedilla, en el edificio de viviendas en la calle Viriato, en el Hotel Florida, etc., por lo que muestra una misma evolución utilizando lenguajes plásticos distintos.

En el teatro Garcia Barbón (fig. 1), del que formaba parte importante la sala de cine Rosaía de Castro, el arquitecto sigue una orientación clasicista academicista, creando un edificio altamente monumentalizado en el que se integran diversas funciones con el fin de rentabilizar la construcción. Utiliza un lenguaje más convencional que en otros proyectos, que contrasta poderosamente con la ruda expresividad de otras obras suyas en la comarca, pero en consonancia con los edificios fuertemente ornamentados que la burguesia viguesa levantaba en el ensanche efectivo de la ciudad.

El nuevo teatro sustituia al antiguo teatro Rosalia de Castro, obra de Domingo Rodríguez Sesmero, que fuera adquirido por don José Garcia Barbón unos años antes de su muerte, acontecida en 1909, con la intención de que la ciudad siguiera contando con un teatro principal, ante la polémica surgida por la posible utilización de los terrenos para edificaciones de tipo comercial. En el mes de febrero de 1910, el teatro sufre un gran incendio que lo destruye totalmente. Los herederos de Garcia Barbón, siguiendo el pensamiento del filántropo, deciden levantar un nuevo edificio, encargándole, ese mismo año, a Antonio Palacios el proyecto, 


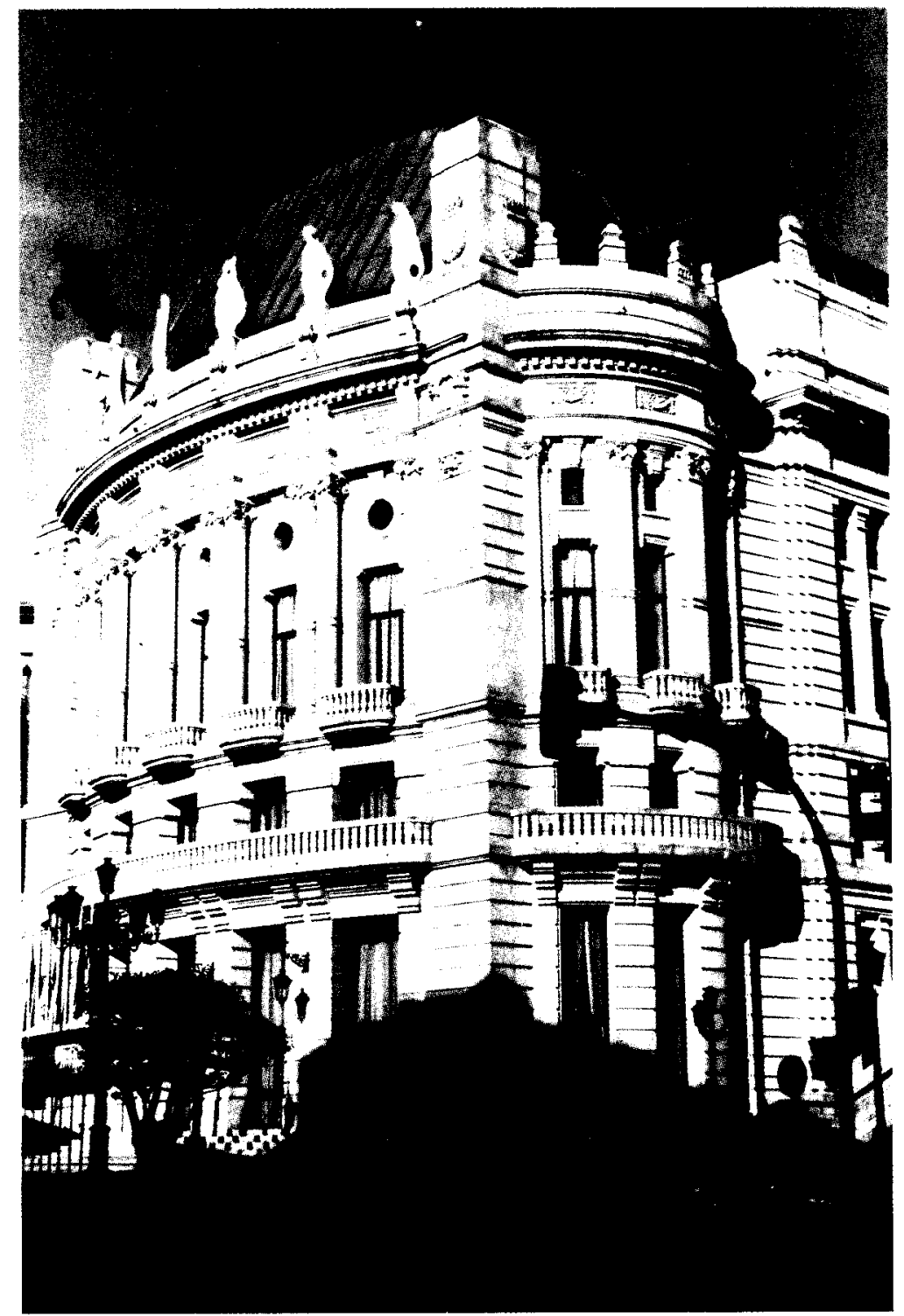

Fig. 1. Fachada principal del teatro Garcia Barbón. Vigo. A. Palacios 
asumiendo el arquitecto los trabajos tras el viaje a Egipto con sus alumnos de la Escuela de Arquitectura de Madrid ${ }^{18}$.

Don Manuel Pérez Conde, en representación de los herederos de García Barbón, presenta, el 11 de abril de 1911, en el ayuntamiento de la ciudad el plano de la planta del nuevo edificio, solicitando licencia para llevar a cabo la cimentación, que concede la corporación municipal el 28 de abril del mismo año ${ }^{19}$. Los trabajos de cimentación ${ }^{20}$ están terminados en el año 1912, ocupando el solar del antiguo teatro y de dos casas contiguas con fachadas a la calle Marqués de Valladares, con lo que obtiene el arquitecto un terreno preferente de $1.900 \mathrm{~m}^{2}$ con frentes a cuatro calles, siendo dos de ellas las más importantes de la ciudad. En abril de 1914, don Manuel Pérez Conde solicita la licencia definitiva de obras, entregando en el ayuntamiento de la ciudad la carpeta que contenía los once planos de la nueva edificación, que, conjuntamente con el plano entregado para realizar la cimentación, componian la totalidad del proyecto ${ }^{21}$. La corporación municipal, en sesión de 17 de abril de 1914, concede los permisos pertinentes, liberando a la nueva construcción del pago de los impuestos correspondientes ${ }^{22}$. El proyecto fue ampliamente conocido y levantó gran expectación entre los vigueses, estando incluso los planos expuestos, durante algún tiempo, en los salones del periódico local Faro de Vigo. Sin embargo, las obras comenzarian a sufrir considerables retrasos, prolongándose las mismas hasta el año 1926.

Palacios diseña un complejo edificio que acoge tres funciones principales e independientes: cinematógrafo, casino y teatro, bajo un ampuloso ropaje arquitectónico. En la interior concede especial importancia al eje: vestíbulo principal, escalera de honor y teatro, que, como en otras obras de marcado carácter ciudadano se enfatiza, generando toda la posterior distribución interna. En este sentido, destaca la complementación del casino y teatro, espacios más aristocráticos del edificio, utilizando para ello la escalera principal como elemento unificador, a la vez que juega con los vacios producidos por las dos salas del casino y con los propios accesos a los anfiteatros principales, prescindiendo de patios interiores. Por esta razón, como sucede en el Círculo de Bellas Artes de Madrid ${ }^{23}$, la distribución interior es compleja, buscando el máximo aprovechamiento

\footnotetext{
${ }^{18}$ FV. $12-|I|-1910$.

${ }^{19}$ AMV. Expediente a Teatro Garcia Barbón. Urbanismo Carpeta: URB-165.

${ }^{20}$ FV, 1-IX-1912.

${ }^{21}$ AMV. Proyecto del Teatro Garcia Barbón. Urbanismo. Año 1914. Carpeta: URB-166.

${ }^{22}$ AMV. Expediente de Cimentación del Teatro García Barbón. Urbanismo. Carpeta: URB-

${ }^{3}$ Véase Pérez Rojas, Javier: Op. cit., págs. 131-140.
} 172. 
del edificio, en un intento logrado de integrar funciones tan diversas dentro de un conjunto altamente monumentalizado. Sin embargo, el cinematógrafo, a pesar de que su distribución interna viene directamente derivada de la ubicación del teatro principal y de su vestíbulo, mantiene una cierta independencia.

La sala de cine Rosalia de Castro se situaba en la planta baja del edificio (fig. 2), manteniendo una entidad propia con respecto a las dos funciones principales, favorecida por el desnivel existente entre las dos calles, por lo que Palacios contempló dos accesos totalmente independientes y principales para el teatro y el cinematógrafo. Esta diferenciación, está también presente en el tratamiento de las fachadas, concediéndole a la principal una entidad propia, enfatizándola con respecto a las demás, remarcando el carácter aristocrático del edificio con sus funciones de teatro principal y casino de la ciudad. La entrada al cinematógrafo se hacia por la calle Marqués de Valladares a través de un vestibulo de $40 \mathrm{~m}^{2}$ con dos amplias salas de descanso a ambos lados, de $54 \mathrm{~m}^{2}$ cada una, comunicadas directamente con un amplio pasillo circular que daba acceso a los palcos y que se comunicaba al exterior por entradas situadas en las calles laterales ${ }^{24}$. La distribución de toda la planta baja se hace en función de la principal, ya que la bóveda del propio cinematógrafo hace de sostén del patio de butacas del teatro y la ubicación de un amplio restaurante de planta oval, como complemento de la sala de proyección, obedece al emplazamiento de gran vestíbulo del teatro. Por esta razón, el patio de butacas del cinematógrafo mantiene una planta circular, situándose la pantalla y un pequeño escenario en sentido contrario al del teatro, por lo que se aprovechaba la superficie que en la planta superior se destinaba a escenario para colocar 11 filas de butacas. La sala, con un patio de butacas con capacidad para 630 espectadores y 14 palcos con 84 sillas, carecía de anfiteatro, ya que el espacio superior estaba ocupado por el propio teatro. Esta sala, diseñada desde un primer momento como cinematógrafo, tenía un uso polivalente, contemplando el arquitecto, la posibilidad de utilizarla en ciertas ocasiones para otros espectáculos, entre los que se incluian los grandes bailes. Cinematógrafo, restaurante y demás dependencias de servicios se comunicaban directamente con la planta principal a través de la escalera central y de dos laterales.

En la planta principal, con acceso por la calle Policarpo Sanz, se situaba un amplio salón oval y dos laterales dedicados a dependencias del casino. Este gran salón, de carácter ampuloso y elegante, en consonancia

${ }^{24}$ "Teatro Rosalia de Castro. Proyecto del nuevo edificio». FV, 8-IV-1914. 


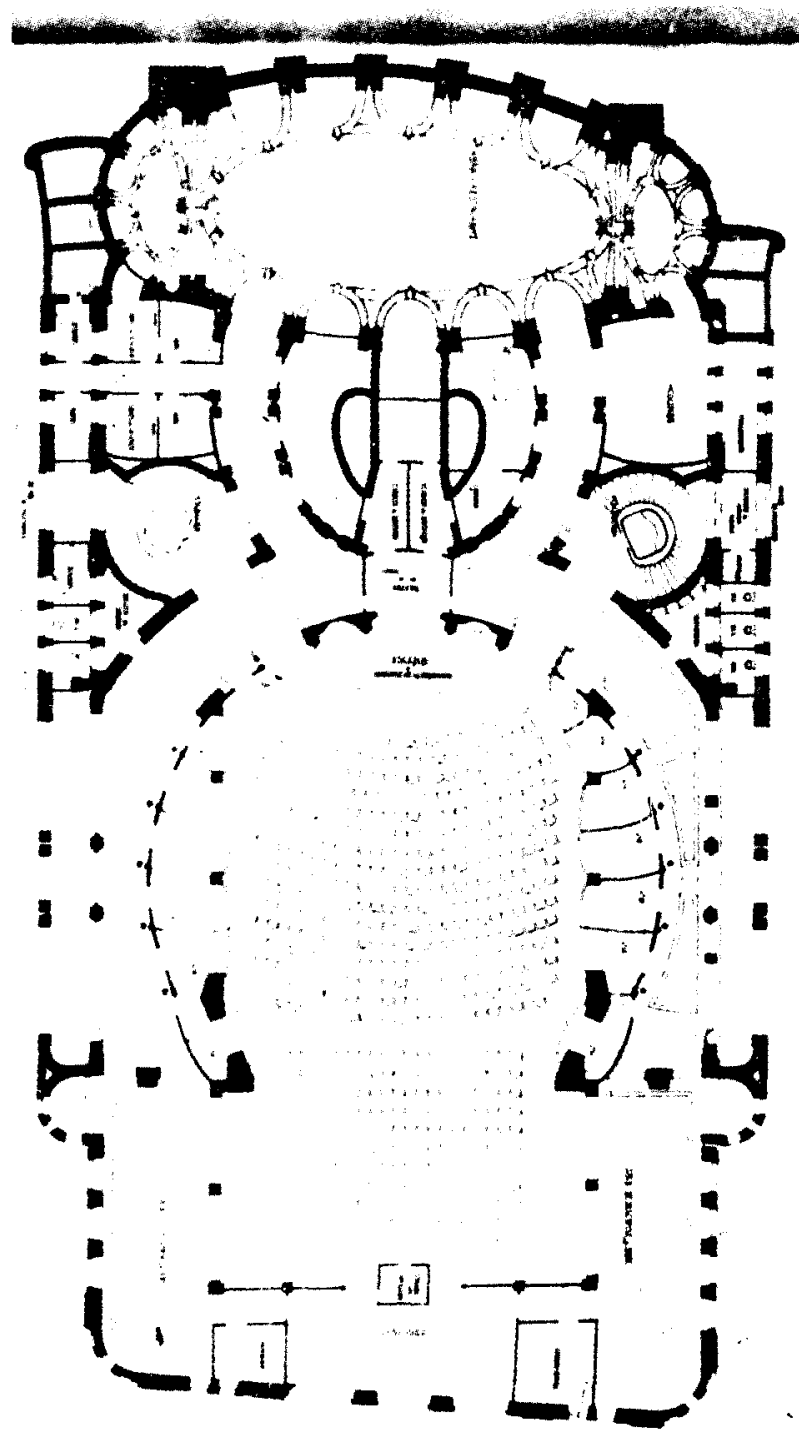

Fig. 2. Planta del cine Rosalia de Castro. A Palacios (Archivo Municipal de Vigo) 
con la monumentalidad del edificio, tenía también un uso polivalente, ya que, según el pensamiento de Palacios, se transformaria en magnífico vestibulo del teatro en las grandes solemnidades, aunque normalmente fuese utilizado como dependencia del casino ${ }^{25}$. No obstante, la concepción del mismo, deriva fundamentalmente de considerar al teatro como elemento primordial de todo el conjunto, ya que el propio vestíbulo, escalera principal y teatro condicionan toda posterior distribución. En relación con la escalera de honor, elemento coordinante de las principales dependencias del edificio, destaca su iluminación natural, con la colocación de una vidriera en la parte superior de la misma, diseñada por el propio Palacios y ejecutada por la casa Maumejean de Madrid ${ }^{26}$, que aporta luz cenital, distribuida por todos los tramos. El patio del teatro presentaba una planta semicircular de $37 \mathrm{~m}$ de diámetro, dividida en sala de butacas y 16 plateas con dos proescenios. Al lado de las plateas, con frente a las calles laterales se ubicaban dos amplias galerias de $40 \mathrm{~m}^{2}$, con función de vestíbulos y comunicadas con los pasillos circulares y con las escaleras laterales. En el entresuelo se situaban dos pequeños salones del casino: billares, sala de lectura, etc., y los accesos a los 16 palcos principales. En la planta tercer emplazaba el anfiteatro principal y catorce dependencias para actores, diseñando para el casino, con frente a la calle principal de Policarpo Sanz, un gran salón de fiestas oval, al que se accedia a través de la escalera principal. En la planta cuarta se disponia el segundo anfiteatro, vestibulos y 14 pequeños espacios para actores. En la quinta se ubicaba el anfiteatro general y una gran sala de $160 \mathrm{~m}^{2}$ para dependencias del casino con dos terrazas a los lados con magníficas vistas sobre la ciudad y la ria. El edificio se terminaba con una mansarda, destinada a vivienda del administrador del teatro y del conserje y con unas monumentales esculturas, que según la prensa local ${ }^{27}$, serian realizadas por el escultor Santiago Bonome con diseños del propio Palacios. En la ejecución del proyecto no se llegó a terminar la parte superior de la edificación.

Es una de las obras más convencionales del arquitecto realizada en tierras gallegas. En el tratamiento de las fachadas, muestra Palacios el deseo de convertir el edificio en punto referencial de los espacios urbanos inmediatos, caracteristica presente en otras obras urbanas de carácter representativo y consustancial a toda su arquitectura. El deseo de monumentalización y de representatividad dentro del medio urbano in-

\footnotetext{
${ }^{25}$ "Ante la apertura del Teatro Garcia Borbón: una interviu con el arquitecto Antonio Palacios", FV, 23-IV-1927.

${ }^{26}$ "El galleguismo de Antonio Palacios en el Teatro Casino", FV, 25-VII-1925.

${ }^{27} \mathrm{FV}, 2-\mathrm{IV}-1925$.
} 
mediato, está todavia presente en 1942, cuando proyecta, para un solar con frente a una de las calles del teatro, el edificio de la banca Viñas Aranda. En la memoria de este proyecto, con cierto anhelo por el suspendido Plan de Extensión y Reforma Interior de Vigo, afirma:

«Por ambas razones y en esta ocasión también por la proximidad del gran coliseo "García Barbón", este edificio además de aquellos destinos obligados, ha de presentar un carácter monumental que ennoblezca este lugar de la ciudad y llene de orgullo emprendedor a sus habitantes...»

«En este proyecto hemos seguido el magnifico ejemplo de ordenación única que seria de desear se extendiera no sólo al solar inmediato de "La Vidriera", sino que se adoptara simétricamente en el ángulo de las calles Rosalia de Castro y Valladares, formando con el gran teatro, escoltado por estos edificios gemelos, el conjunto arquitectónico más importante de la ciudad hasta el presente y esto sin mayor dispendio que con cualquier otra evolución incongruente" ${ }^{28}$.

El carácter monumental del edificio se refleja principalmente en su fachada principal, en la que concentra toda la ornamentación, mostrando un lenguaje clasicista academicista con ciertas influencias derivadas de la Ópera de Paris de Charles Garnier, aunque reelaboradas dentro de la tendencia del arquitecto a buscar una arquitectura personal. Presenta un leve movimiento, fruto de la curvatura de la fachada, derivada de acusar al exterior las plantas ovales del vestibulo y salón de fiestas del casino, que junto a la profusa decoración, otorga a esta fachada un cierto aire barroquizante. Existe un claro deseo de monumentalización, quizá derivado del carácter eminentemente ciudadano de la obra, mostrando Palacios todo su virtuosismo decorativo. Sin embargo, está plenamente ambientada con la arquitectura circundante, en la que las diversas tendencias del momento dejan siempre un amplio espacio para mostrar el excelente trabajo del cantero. Esta fachada aparece enmarcada por dos grandes pilastras y dividida, en su parte inferior, por una balconada corrida, sustentada por gruesas ménsulas. Utiliza, en el cuerpo superior, un orden gigante con columnas pareadas de gran clasicismo terminadas en capiteles compuestos que organizan verticalmente la fachada y que se relacionan con las utilizadas en los edificios comerciales y bancarios que proyecta en este momento. En los intercolumnios sitúa amplios ventanales acristalados que se complementan en su parte superior con un óculo profusamente decorado. En la parte superior de la fachada coloca dobles

${ }^{28}$ AMV. Proyecto y memoria del edificio Banca Viñas Aranda. Urbanismo. Año 1941. Carpeta: URB-119. 
triglifos y en las metopas pequeños colgantes de guirnaldas vegetales, detalle ornamental también utilizado en el Pabellón de la Fuente (1908) del vecino balneario de Mondariz.

Detrás de la ampulosidad y academicismo de la fachada principal aparece un lenguaje más actual en las fachadas laterales y posterior que presentan un mayor rigor formal y economia en la ornamentación, destacando los grandes paños acristalados de las dos laterales. Aunque las fachadas esconden la compleja distribución interna del edificio, su tratamiento está relacionado con las funciones de la edificación, ya que concentra todo el virtuosismo decorativo en la principal que da acceso a las partes más aristocráticas del edificio: casino y teatro principal de la ciudad. Sin embargo la fachada posterior (fig. 3), en la que se situaba el elemento más popular de la edificación, el cinematógrafo, presenta una depuración de la ornamentación y una simplificación de formas, aportando la novedad de acoger bajo un gran arco, un amplio ventanal de siete $\mathrm{m}$ de ancho por 11 de alto que unificaba toda la composición y aportaba luz natural al escenario del teatro. Esta solución seria un predecente de la utilizada por Palacios en el Banco Mercantil de Madrid y en el proyecto, no realizado de la Sociedad de Autores.

El edificio, que en su ropaje externo presenta el excelente granito de las canteras de Sierra Castrelos, manifiesta un cierto progresismo en la utilización de hormigón en su estructura interna, sobre todo en la bóveda nervada del cinematógrafo Rosalia de Castro que hace de suelo del teatro principal (fig. 4), solución muy comentada en su momento. En la propia decoración de la sala del cinematógrafo mostraba Palacios los nervios de esta bóveda, construida hacia principios del año 1924 (fig. 5). Los trabajos en hormigón fueron realizados por la casa Santigo Rodriguez, bajo la dirección del ingeniero Ramón Beamonte que ya estuviera al frente de las obras de cimentación ${ }^{29}$.

La diversidad e independencia de las funciones del edificio se manifiesta también en los actos inaugurales, ya que las diversas instalaciones se fueron abriendo al público por etapas, lo que también se relacionaria con la progresiva terminación de la obra que en su totalidad quedó incompleta. El casino ${ }^{30}$ seria el primero en celebrar el solemne acto de apertura el 7 de noviembre de 1926. El día 30 del mismo año se inaugura el cinematógrafo con una función benéfica, celebrándose al dia siguiente el acto de apertura al público con la proyección de la película Mare Nos-

\footnotetext{
${ }^{29}$ AMV. Correspondencia de obras del Teatro Rosalia de Castro. Urbanismo. Carpeta: URB-118.

${ }^{30} \mathrm{FV}, 9-\mathrm{XI}-1926 . \mathrm{PG}, 7-\mathrm{XI}-1926$
} 


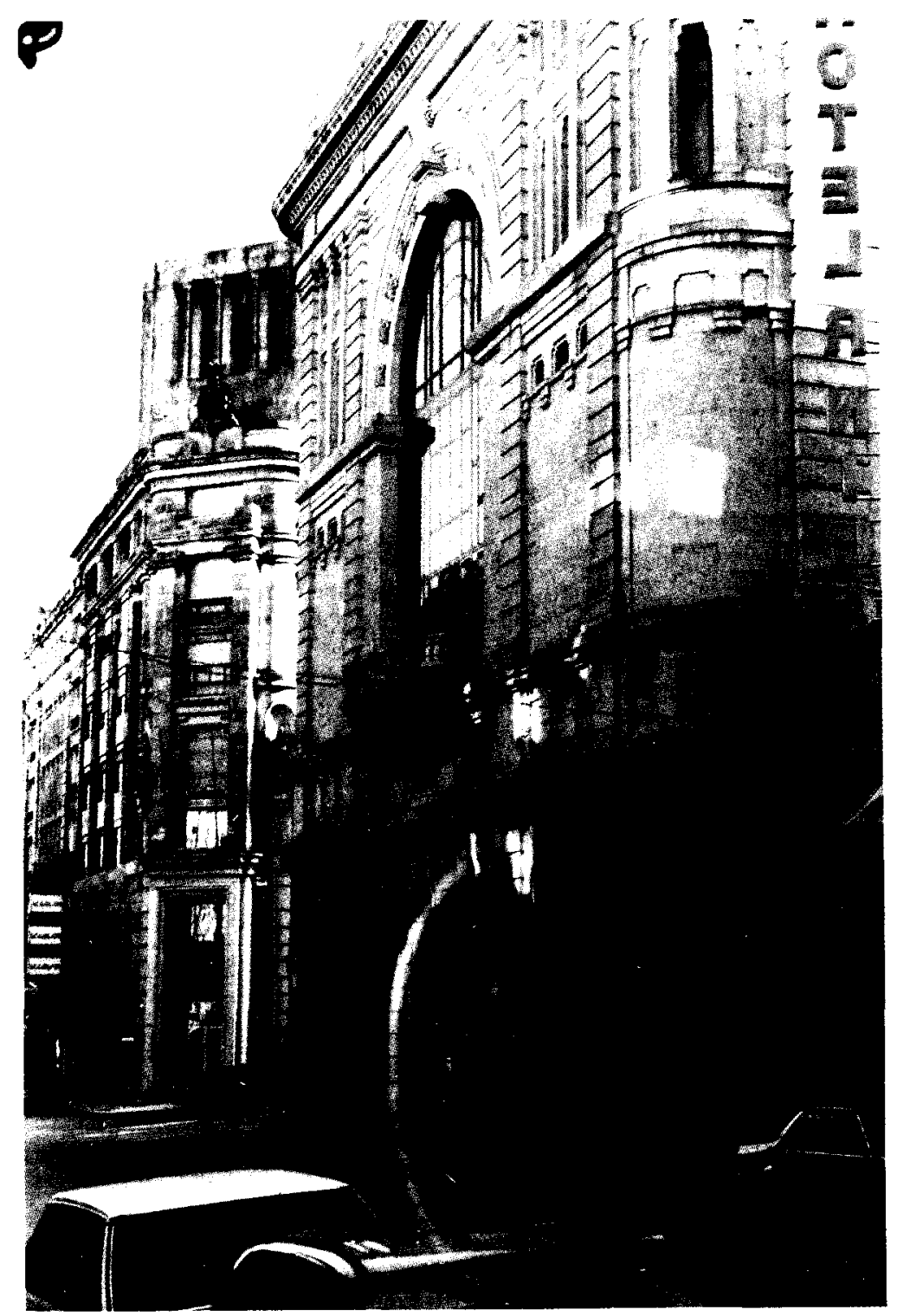

Fig. 3. Fachada posterior del teatro Garcia Barbón. Acceso del cine Rosalia de Castro y Banca Viñas Aranda (al fondo). A. Palacios 


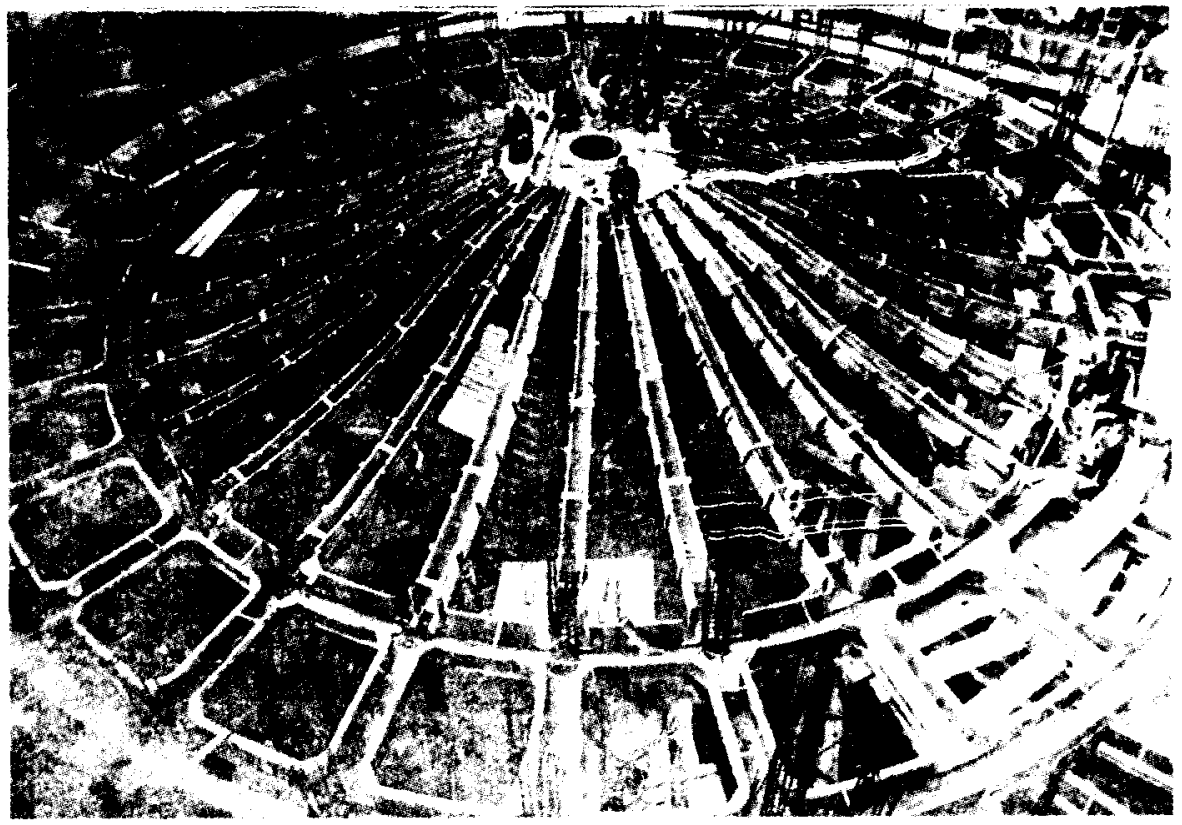

Fig. 4. Bóveda nervada del cine Rosalia de Castro. Construida a principios de 1924

trum sobre una obra de Blasco lbáñez ${ }^{31}$. La inauguración del teatro ${ }^{32}$ se retrasaria hasta el 23 de abril de 1927.

El cine Rosalia de Castro se convertiría en la sala más elegante de la ciudad, teniendo una larga vida, a pesar de ser dedicado por algún tiempo a sala de baile y de sufrir algunas reformas, llegándose a instalar una cafetería en su vestibulo, por lo que quedó reducida su capacidad. Todo el edificio sufrió una completa remodelación, no exenta de polémica, entre los años 1982 y 1984, al ser adquirido el inmueble por la Caja de Ahorros de la ciudad para transformarlo en centro cultural, conservándose la función de teatro principal de la ciudad, quedando el antiguo cinematógrafo convertido en auditorio, por lo que conserva, en parte, su primitiva función.

FV, 26, 30, 31-XII-1926. PG, 30, 31-XII-1926.

32 Vida Gallega, núm. 339, 30-IV-1927. FV, 23, 24-IV-1927. 


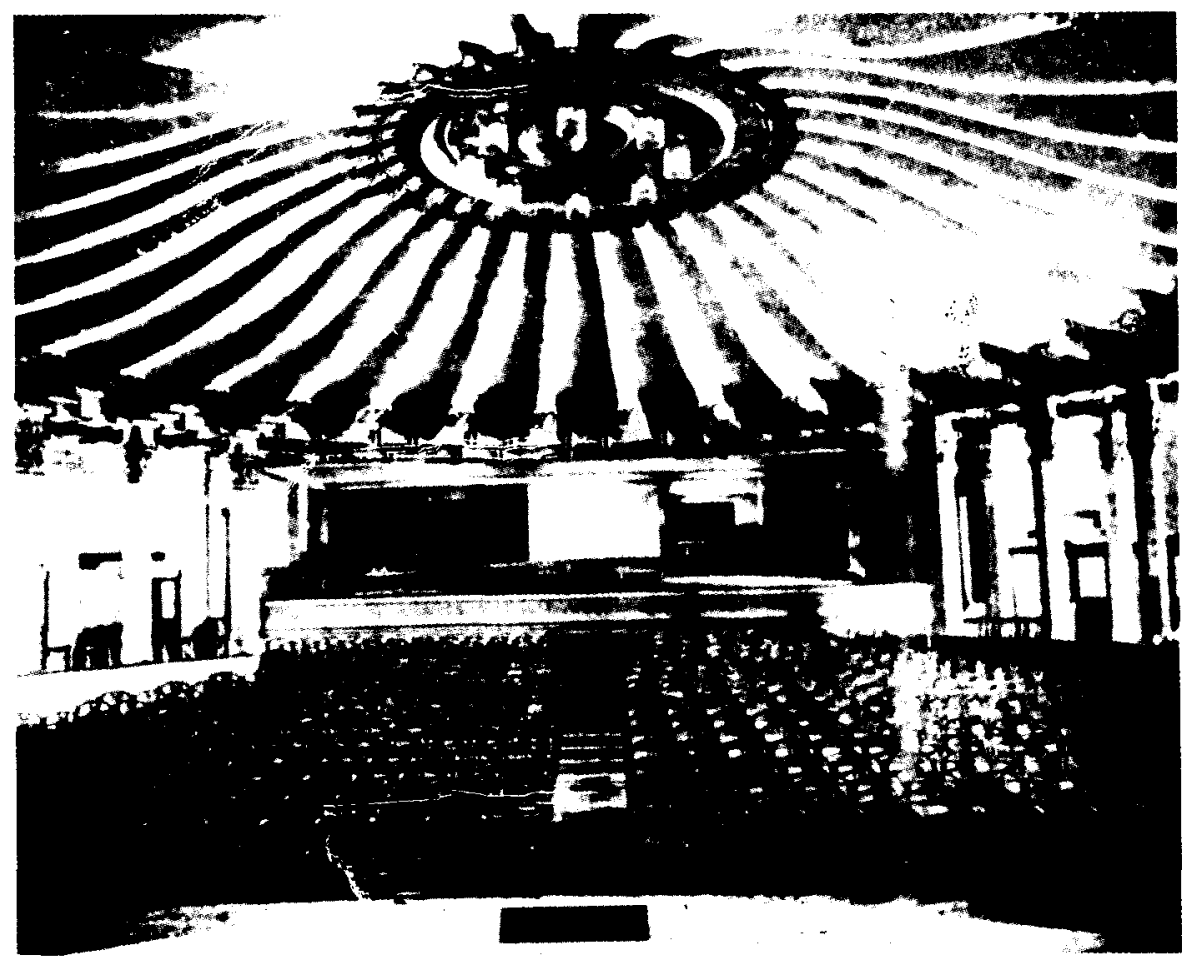

Fig. 5. Aspecto interior del cine Rosalia de Castro en el momento de su inauguración, 1926

\section{CINE FRAGA}

Después de inaugurado el cine Rosalia de Castro, pasará un largo periodo, que dura hasta la terminación de la Guerra Civil, para que se construyan nuevas salas de cine. En esta segunda etapa destacan, por la arquitectura que incorporan y por las relaciones que mantienen con la que se realiza en estos momentos en la ciudad, el cine Fraga y el Cinema Radio. Junto a la citada sala Rosalía de Castro, son ejemplo de la importancia y categoría que este espectáculo alcanza, presente también en la trayectoria personal de los arquitectos que proyectan estas salas. Antonio Palacios y Gutiérrez Soto de amplia resonancia en la capital de España, dentro de tendencias bien distintas. Francisco Castro y Pedro Alonso, de relevante importancia dentro del contexto de la arquitectura local y gallega en general, por la introducción, en la ciudad, de las nuevas corrientes internacionales del momento. 
Con la intención de construir la mejor sala de cine de la ciudad, Isaac Fraga Framil, uno de los más importantes empresarios exhibidores gallegos de este momento, encarga a Luis Gutiérrez Soto, en el año 1942, el proyecto de un gran edificio que prestigiara a la propia empresa. En esta decisión pesaria la gran fama alcanzada por este arquitecto en los proyectos realizados en Madrid y en otros puntos de España.

Luis Gutiérrez Soto, uno de los arquitectos más importantes de la generación que se sitúa entre la de Palacios, Otamendi, Anasagasti, etc. y la de los arquitectos del GATEPAC, termina sus estudios en 1923, comenzando a trabajar con López Otero, hasta que en 1925 realiza sus primeras obras en solitario. El primer cine que lleva a cabo y que le da gran fama, es el Callao de Madrid (1926), en el que se relacionaria con un art déco cosmopolita ${ }^{33}$, recogiendo el vocabulario de la Exposición de Arte Decorativas de París de 1925. El cine Europa (1927) presenta un lenguaje más renovador en el que están presentes las influencias de Mendelsohn. La tendencia hacia un lenguaje inspirado en formas de barcos y aerodinámicas se acentúa en el Barceló (1930), una de las obras de carácter más radical e internacional del arquitecto ${ }^{34}$, presentando además un perfecto aprovechamiento del espacio al situar el patio de butacas en diagonal a las calles laterales. Esta arquitectura aerodinámica está presente en gran parte de su obra anterior a la Guerra Civil. La piscina Isla de Madrid (1931), el primitivo aeropuerto de Barajas, el cine Góngora de Córdoba (1932), la piscina de las Arenas de Valencia, son ejemplos significativos de esta arquitectura dinámica de Gutiérrez Soto. Una orientación más racionalista está presente en el edificio de la calle Almagro de Madrid (1934), donde utiliza el balcón-terraza para aumentar el número de habitaciones exteriores, solución que habría de tener gran influencia en la arquitectura madrileña de décadas posteriores ${ }^{35}$. Acabada la Guerra Civil, se deja contagiar por las corrientes oficiales del momento, estando presentes, sobre todo, en el Ministerio del Aire. En este periodo su producción de cines continúa ${ }^{36}$ : Montera de Madrid (1939), cine Sevilla (1939), Generalife de Granada (1941), Levante de Valencia (1962) y multicines Lauria de Valencia (1972).

Cuando en 1942, proyecta el cine Fraga para la ciudad de Vigo es un afamado proyectista de cines, con actuación progresista en ios realizados

${ }^{33}$ Perez Rojas, Javier, Art Déco. Màdrid, Càtedra, 1990, págs. 508-517.

${ }^{34}$ Ibidem. págs. 602-606.

3 CHUECA Goltia, Fernando, "El siglo xx. Las fases finales y España", en Historia de la arquitectura occidental. Madrid, Dossat, 1980, págs. 301-303.

${ }^{36}$ Miguel, Carlos de, et alli, La obra de Luis Gutierrez Soto. Madrid, COAM, 1978, págs. $301-331$ 
en el período anterior a la Guerra Civil. Sin embargo en éste, se dejará contagiar por las tendencias del momento y por la tradición, a lo que no es ajeno el peso de la arquitectura de la ciudad, en la que se mantenía el gusto por la rica ornamentación en granito, tendencia que habia comenzado a romper, en la década anterior, Francisco Castro Represas. Será precisamente este arquitecto el que conciba la idea de crear un cine en el solar que actualmente ocupa, buscando una utilidad para este céntrico terreno, propiedad de la familia Gándara y Haz. Por esta razón, realiza en el año 1933 el proyecto ${ }^{37}$ de una sala de cine que contrasta poderosamente, por el lenguaje empleado, con la realizada posteriormente. El proyecto (fig. 6), concebido con gran impulso renovador, es un ejemplo de la nueva arquitectura que Castro Represas comienza a introducir en la ciudad, en la que se alejaba totalmente de las referencias ornamentales de signo historicista utilizando un lenguaje limpio, en el que está presente la influencia de las nuevas formas que comenzaban a implantarse en la capital de España durante su periodo de formación, de la que son ejemplos las obras del propio Gutiérrez Soto, la gasolinera de Porto Pi de Fernández Saw. en la calle de Alberto Aguilera o el edificio Carrión

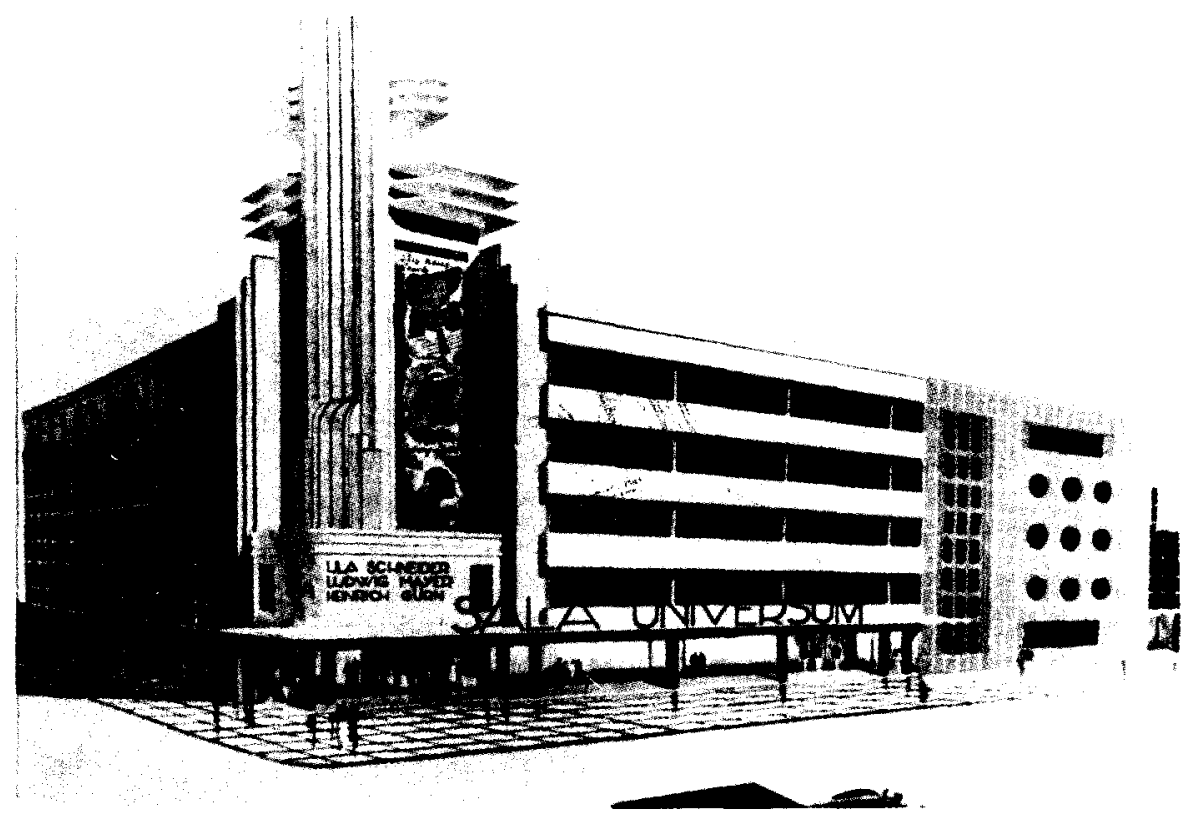

Fig. 6. Proyecto de cinematógrato. Francisco Castro Represas, 1933

37 Archivo de los arquitectos Francisco Castro y Pedro Alonso (ACA). Año 1933. 
de Feduchi y Eced. También estarian presentes los impulsos de un racionalismo más ortodoxo, representado por los escritos y obras de los arquitectos miembros del GATEPAC. En el proyecto muestra las influencias de la arquitectura dinámica que durante este período se había incorporado con gran fuerza a muchas salas de cine, a la que Pérez Rojas denomina art déco aerodinámico ${ }^{38}$ y las de un racionalismo no ortodoxo, en el que pervive un cierto gusto decorativo, presente en el elemento referencial del edificio, representado por una esbelta torre terminada en formas redondeadas y en la que muestra claramente las formas de la arquitectura aerodinámica. Destacan también los cambios en el tratamiento de las fachadas y los grandes paños acristalados que otorgan al conjunto una gran riqueza plástica, aún manteniendo la limpieza de líneas.

De un período inmediatamente anterior a la concreción del proyecto definitivo, presentado en el ayuntamiento de la ciudad ${ }^{39}$ en junio de 1943 y aprobado en enero de 1944, es otro proyecto, conocido por un gran dibujo acurealado (fig. 7), que se atribuye al propio Gutiérrez Soto ${ }^{40}$. Este primer trabajo, que se aparta totalmente del llevado a cabo con posterioridad, presenta un lenguaje de signo racionalista, en consonancia con los edificios de viviendas que realiza a partir de la obra realizada en la calle Almagro de Madrid. En el conjunto del proyecto, que presentaba una gran pureza de formas, se integraba una gran sala de cine y un edificio de viviendas y oficinas. La parte destinada a cine, remarcada claramente en el conjunto, manifiesta cierto gusto por las formas dinámicas, presentes en el vestibulo y en el enlace del cuerpo principal del cine con la alta torre de viviendas, elemento referencial del conjunto. En el proyecto, destacan los grandes ventanales acristalados del cine, ya utilizados en otras obras anteriores, como el cine Europa de Madrid. Este primer trabajo, que destacaba por su modernidad en relación con el llevado a cabo, seria rechazado por Isaac Fraga, pensando en la construcción de un edificio majestuoso que se relacionará con el arte gallego de tiempos pasados. Después de un viaje que realizabn ambos por la geografía gallega, con estancia de varios dias en Santiago, lleva a cabo Gutiérrez Soto el proyecto definitivo, manifestando en la memoria que, en la parte estética no

\footnotetext{
${ }^{38}$ Pérez Rojas, J., Art Déco, Op. cit., págs. 593-601. Señala los límites imprecisos entre un racionalismo inspirado en las formas de barco y aerodinámicas y un art déco avanzado, futurista y moderno.

${ }^{39}$ AMV. Expediente teatro cine Fraga. Urbanismo. Carpeta: URB-119.

${ }^{40}$ Archivo de los arquitectos Fraga Fernández. Vigo. La información sobre este primer proyecto, del que solo se conserva este gran dibujo (no firmado y sin fechar), fue recogida en el estudio de estos arquitectos, nietos de Isaac Fraga, empresario que mandó construir el cine.
} 
Arquitectura y cinematógrafo en la ciudad de Vigo: Palacios, Gutiérrez ...

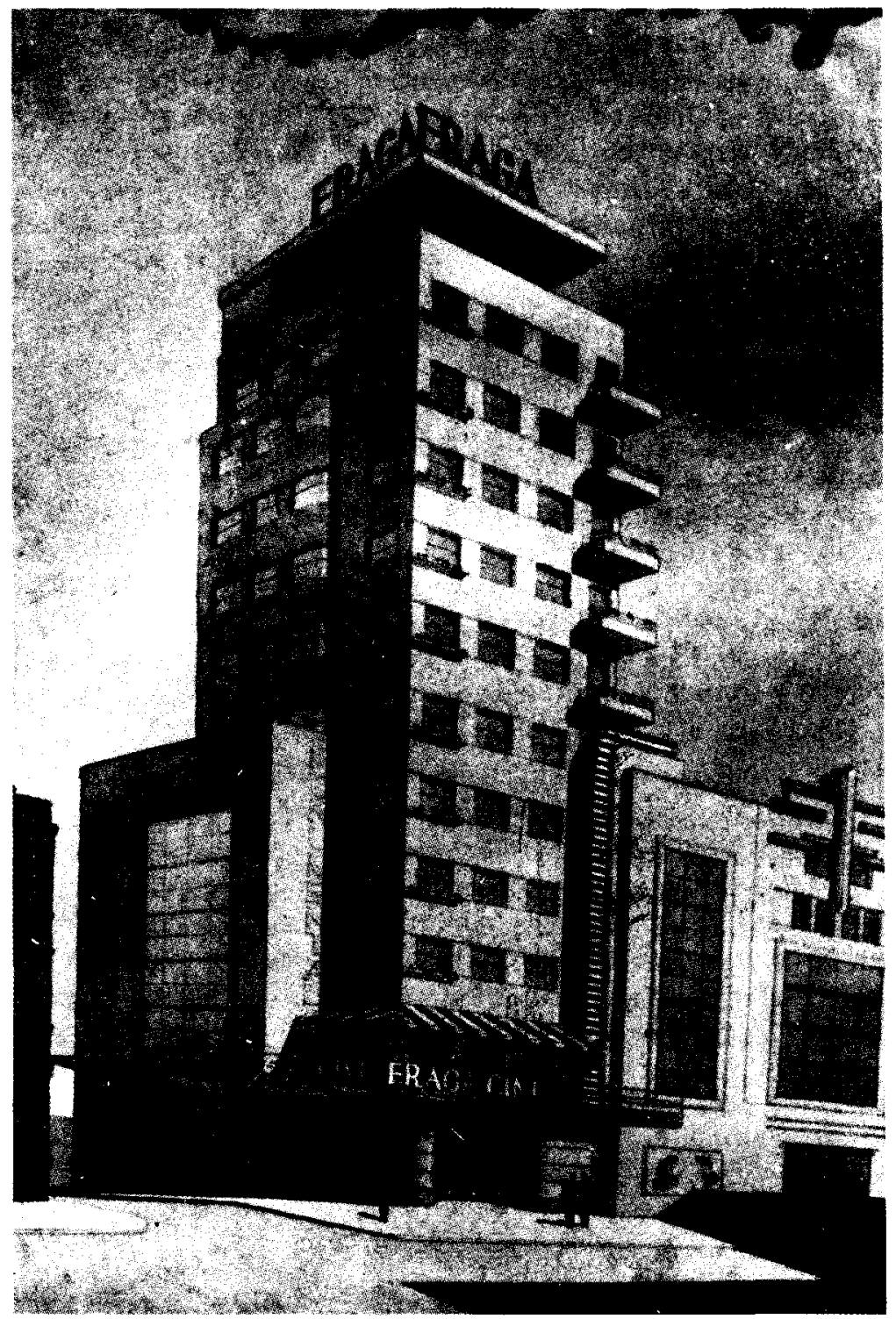

Fig. 7. Proyecto para cine Fraga. Gutiérrez Soto 
se escatimará detalle, procurando armonizar y ambientar el edificio dentro de la tradición gallega:

"Tanto en la parte técnica y constructiva como en la estética y decorativa, no se escatimará detalle para lograr el máximo confort del público, con amplios vestíbulos y salas de espera para casos de lluvias, procurando ambientar la arquitectura del edificio con la tradición galaica del granito en su verdadero empleo..." ${ }^{4}$.

El edificio, en su ornamentación exterior (fig. 8), se aparta de los grandes cines de carácter progresista que el arquitecto habia construido en Madrid y es muestra de la pervivencia del gusto por una arquitectura fuertemente ornamentada y de base historicista en algunos ambientes de la ciudad, sobre todo cuando se trata de llevar a cabo un edificio referencial y significativo dentro del conjunto urbano, lo que conlleva el rechazo de la arquitectura potente y moderna del proyecto anteriormente citado. También se relacionaria con el cambio de rumbo que toma parte de la arquitectura española tras la finalización de la Guerra Civil, bajo las directrices del nuevo régimen, creando un ambiente artificial, que llevó a algunos arquitectos a buscar, por un corto periodo de tiempo una arquitectura genuinamente española que resaltase los valores nacionales, como dice sintió Gutiérrez Soto, cuando proyectó el Ministerio del Aire ${ }^{42}$, en el que está presente el modelo oficial herreriano. El teatro cine Fraga se situaria en un periodo ecléctivo del arquitecto, tras el advenimiento del régimen franquista y se relacionaria, en el lenguaje plástico utilizado, con otras obras suyas de este momento, principalmente el Palacio Marchs de Palma de Mallorca.

El Edificio se ubica en la esquina de las calles Uruguay e Isabel II, en una de las zonas más céntricas y preferenciales de la ciudad, ocupando un solar de 1.380 metros cuadrados. Según el proyecto original ${ }^{43}$, fechado en Madrid en 1942, se estructuraba en cuatro partes principales: local destinado a teatro y cine, salón de fiestas, salón de té y oficinas de alquiler o de uso privado de la empresa. Aprovechando el desnivel de la calle sitúa en los sótanos una gran sala de fiestas con dos alturas en su interior, función que todavia desempeña en la actualidad. En la más baja se situaba la propia pista de baile, plataformas para la orquesta, guar-

"AMV. Expediente teatro cine Fraga: memoria. Urbanismo. Carpeta: URB-119.

${ }_{42}$ FLORES, Carlos, Arquitectura española contemporánea, 1880-1950. Madrid, Aguilar, 1989, Tomo I, pág. 230.

${ }^{43}$ AMV. Expediente cine Fraga. Proyecto y memoria. Urbanismo. Año 1942. Carpeta: URB-119. 


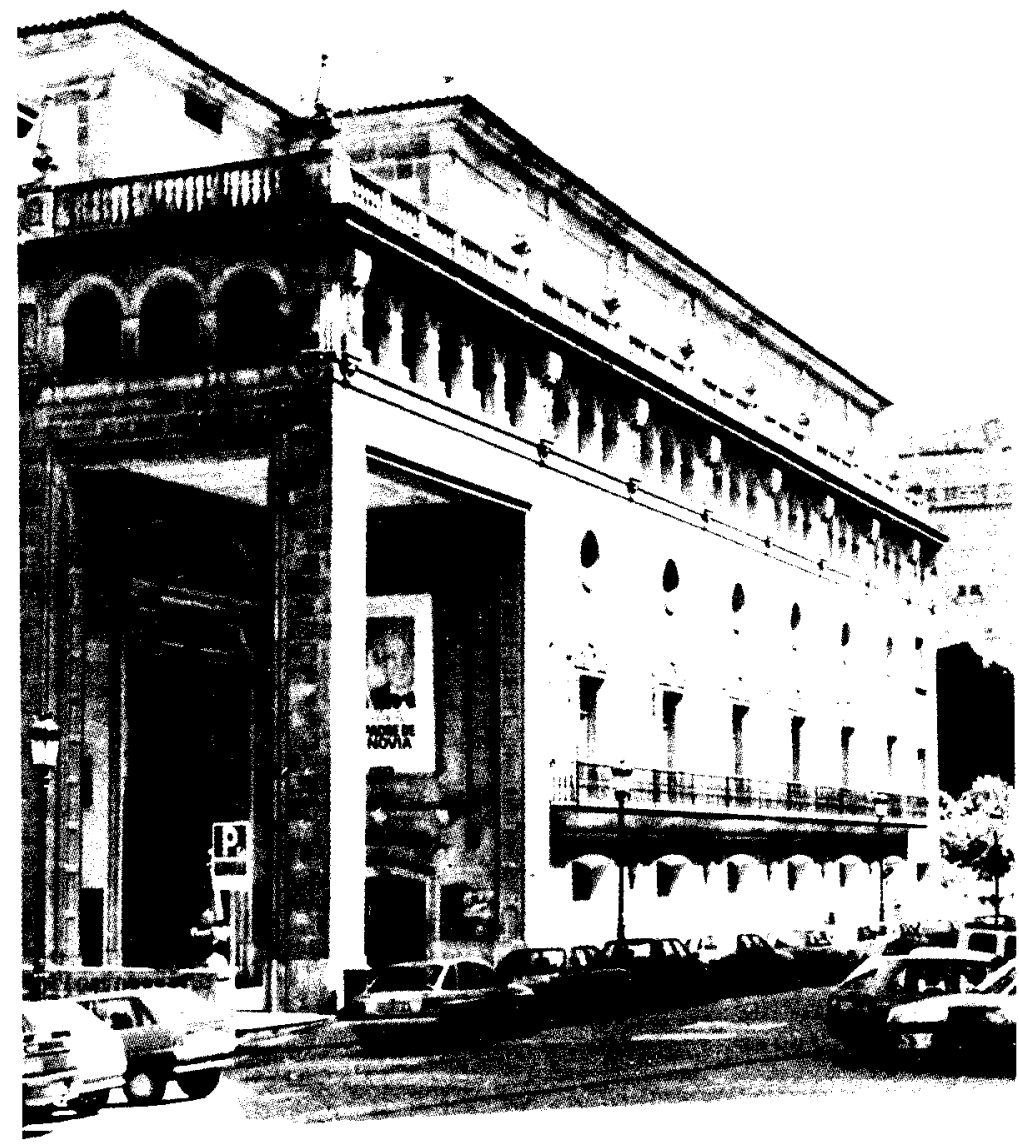

Fig. 8. Cine Fraga Vigo. Gutiérrez Soto 
darropas, etc. La superior, con un gran vacio central, estaba dispuesta a modo de anfiteatro sobre la pista de baile y en ella se situaba el servicio de cafeteria y el vestíbulo principal. En el primer sótano, además de la planta alta de la sala de fiestas, se disponia un salón de té que se comunicaba con la propia sala, con entrada independiente por un vestibulo especial, situado en el costado del porche principal. Esta sala además del servicio de cafeteria contaba con una pequeña pista de baile.

En la planta principal se situaba el cine, al que se accedia a través de un ostentoso porche de formas rectangulares, en el que destaca la gran entrada acristalada que conduce al vestíbulo principal, enmarcada por una rica ornamentación en granito de base neobarroca. En la entreplanta, aprovechando los vacios del vestíbulo del cine, se situaban el bar y los accesos al primer anfiteatro, que se realizaban desde la planta principal a través de dos escaleras laterales. La llegada del público al anfiteatro principal se efectuaba por una amplia escalera terminada en un vestíbulo de distribución y sala de espera con bar de dobles mostradores (fig. 9). Desde el fondo del anfiteatro se accedia a la cabina de proyección, en la que se situaban dos pequeñas salas para la conservación y manipulación de películas. En toda la fachada lateral de la calle Uruguay, se situaban las salidas del propio cine y de la sala de fiestas. El edificio se completaba con un local de dos plantas en la fachada de la calle Isabel II, oficinas de alquiler en las plantas entresuelo y superiores, con frente a la citada calle y una pequeña sala de proyecciones para pruebas (figs. 10 y 11).

En la memoria del proyecto, que aparece firmada en 1942, se hace constar la intención de crear un edificio para cine, único en su género en la ciudad. Este deseo de enfatización está presente en la elección del lenguaje ornamental de sus fachadas (figs. 12 y 13), en las que se muestra un historicismo de base renacentista y barroca, buscando, en esta mirada al pasado, la magnificación de un edificio dedicado a un espectáculo moderno, cuando por las propias características del espectáculo, este tipo de edificios se adaptaban mejor que otros, a recibir las incorporaciones de las nuevas corrientes arquitectónicas. La monumentalidad está presente en el ampuloso porche de entrada, de formas cuadrangulares y considerables dimensiones y al que el arquitecto concede un tratamiento especial, buscando romper la pesadez de la edificación. En la memoria ${ }^{44}$ lo justifica señalando la importancia que tendrá en días de lluvia debido al carácter del clima gallego.

${ }^{44}$ Ibidem 


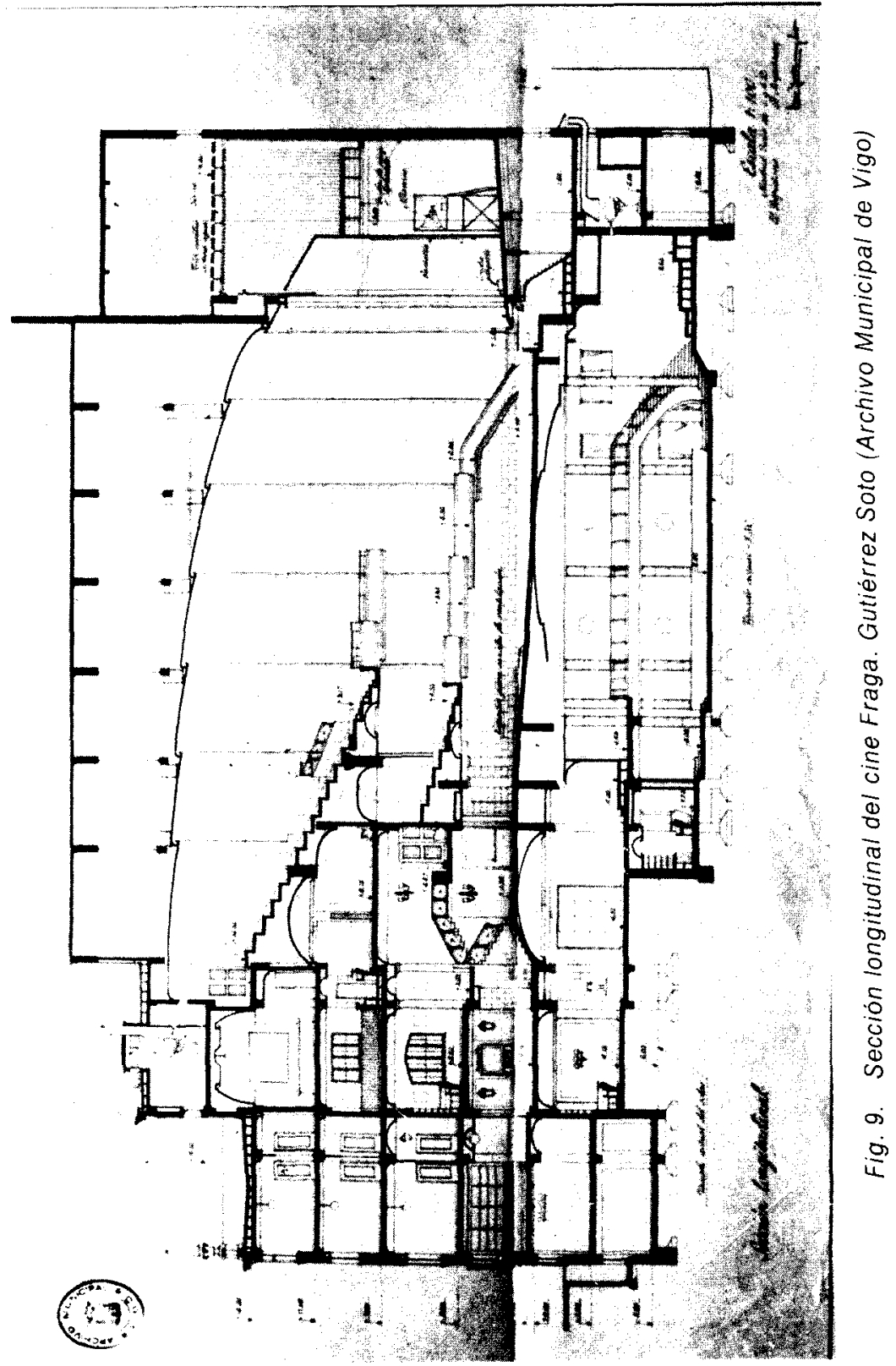


1)

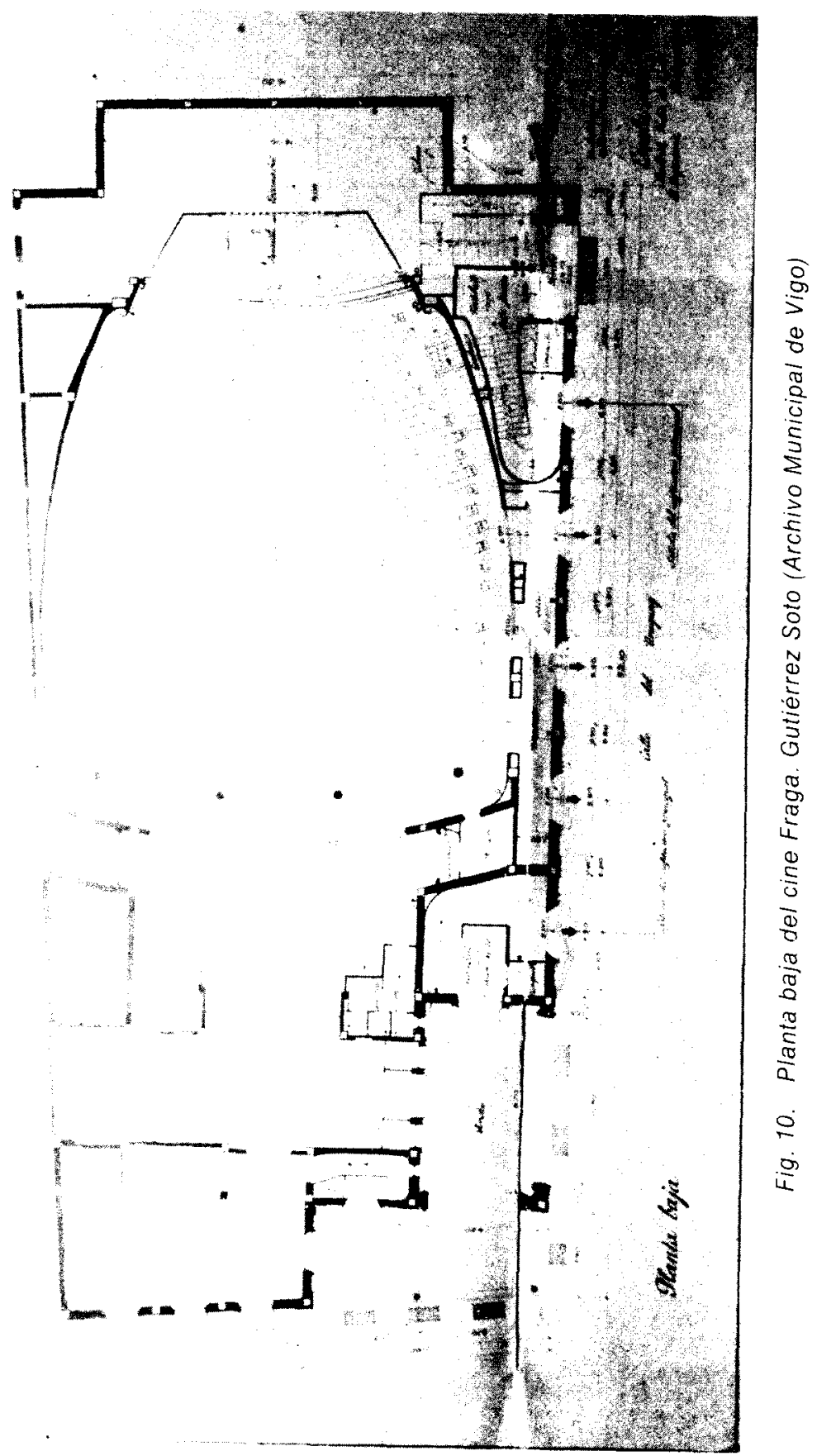


Arquitectura y cinematógrafo en la ciudad de Vigo: Palacios, Gutiérrez ...

$\infty$

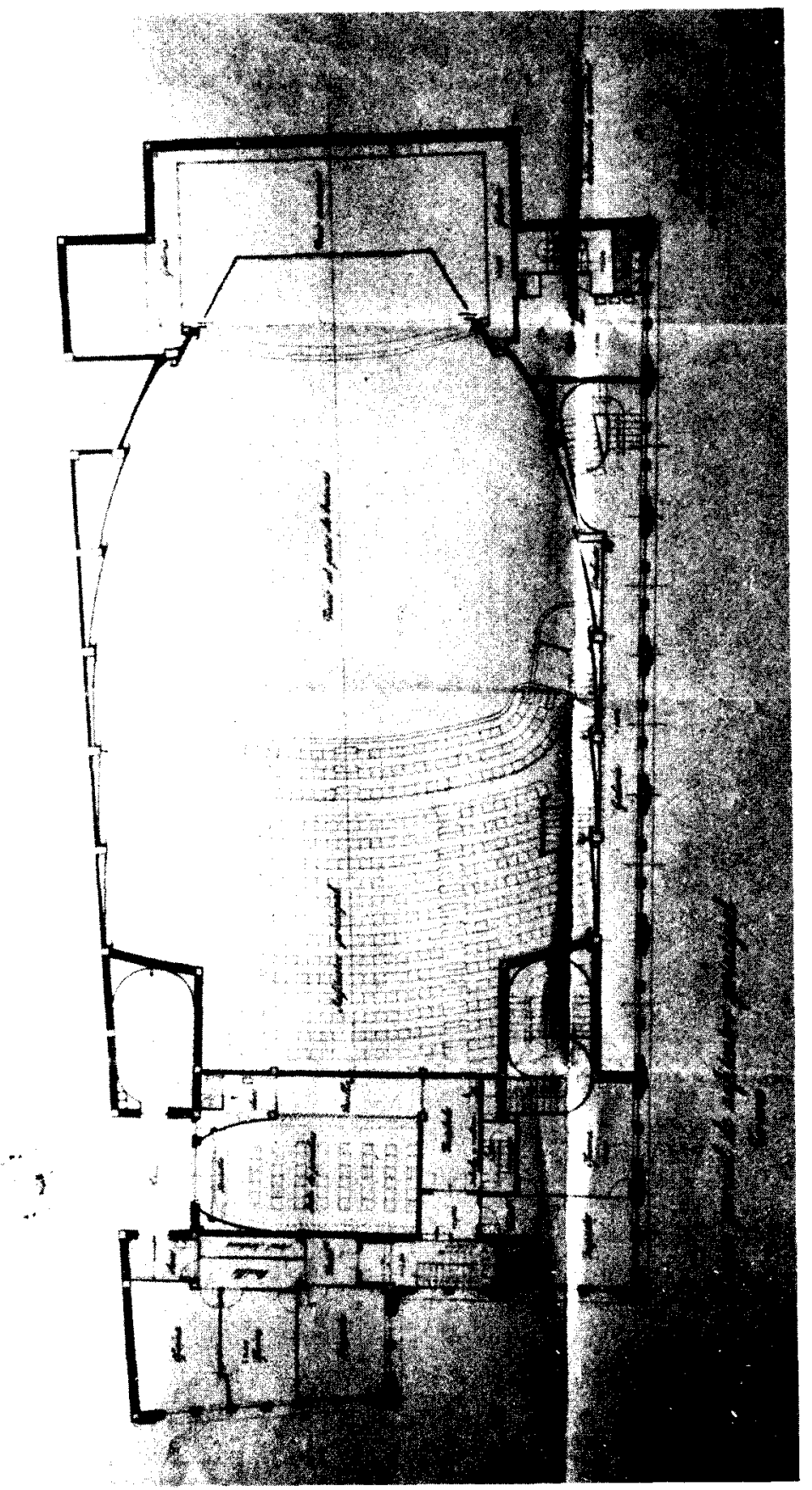

$\stackrel{\circ}{9}$

8

$\bar{\pi}$

$\frac{2}{4}$

$\stackrel{8}{5}$

$\stackrel{0}{2}$

$\frac{\hat{c}}{4}$

용

$\stackrel{N}{2}$

过

8

T2

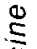

(1)

to

$\frac{2}{5}$

5

운

$\pm$

E

$\frac{1}{0}$

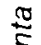

$\frac{\pi}{2}$

$=$

is 
N

5
5
5

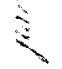

$-5$

s

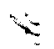

5

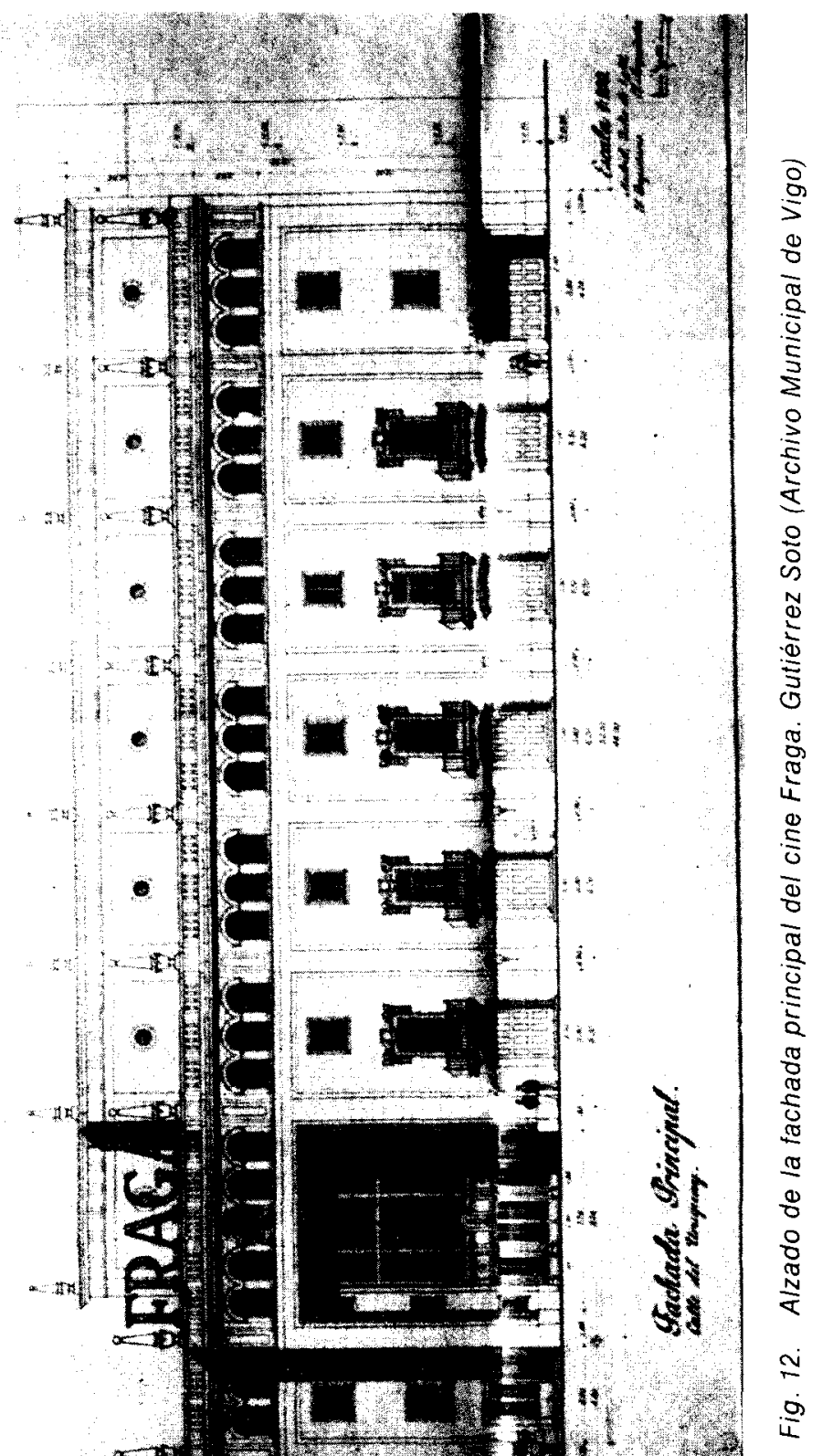




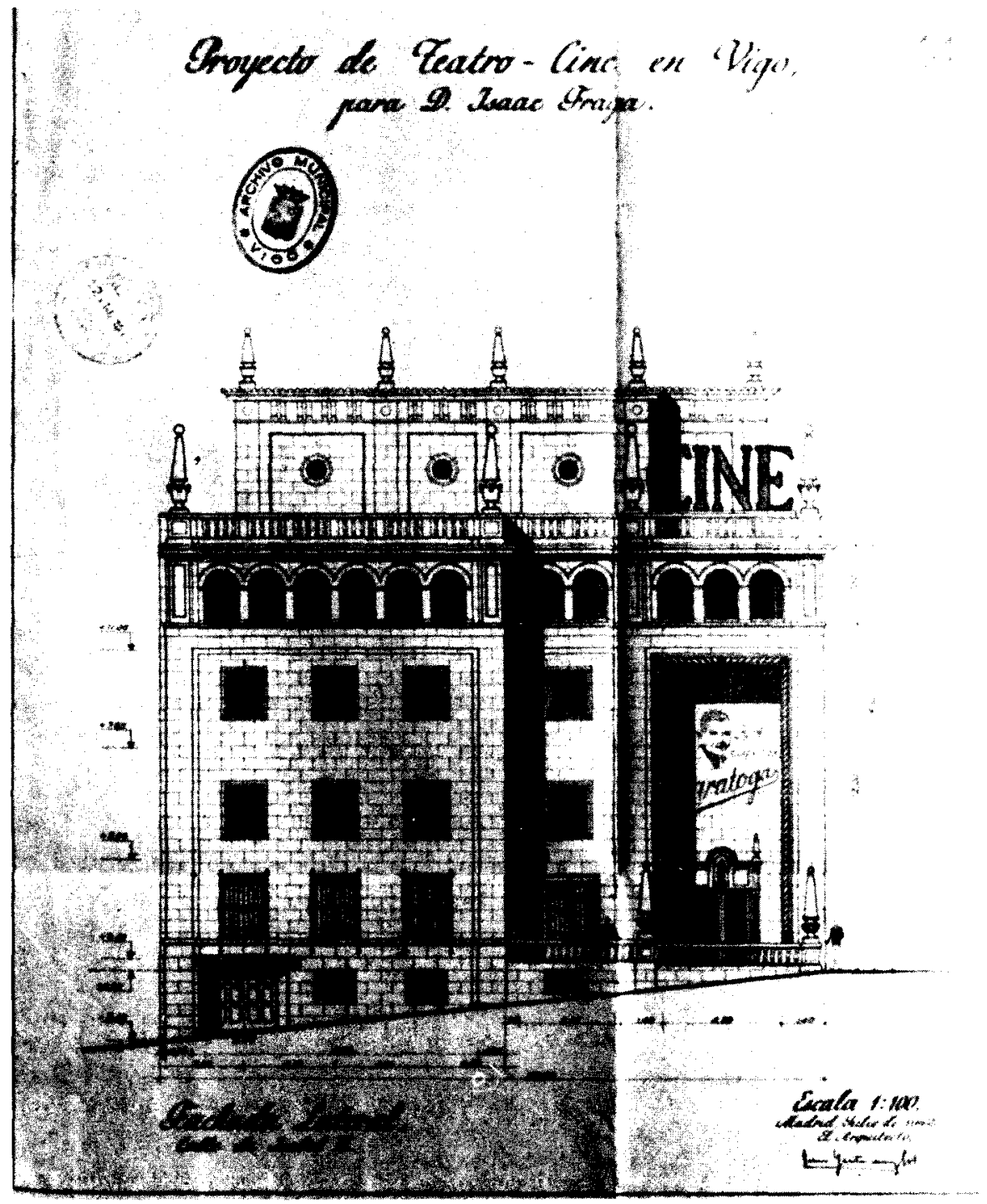

Fig. 13. Alzado de la fachada lateral del cine Fraga. Gutiérrez Soto (Archivo Municipal de Vigo) 
El cine fue proyectado con amplitud y capacidad, ya que su aforo fue pensado para 1.758 localidades, de las que correspondian 844 al patio de butacas, 274 al anfiteatro situado en el entresuelo y 640 al anfiteatro principal. En la dirección de las obras colaboraria el arquitecto Antonio Fraga Framil, hijo de propietario, que habia terminado su carrera en los años en que comienza a levantarse el edificio. La estructura general del edificio fue realizada en hormigón armado, utilizando para las fachadas granito del pais. Un granito de mayor calidad, procedente de las canteras de Castrelos, fue utilizado en las jambas, pilastras, detalles ornamentales (figs. 14 y 15) donde muestra el virtuoso hacer de los canteros que, desde principios de siglo, habian cambiado la fisonomía de la ciudad. En la utilización de una virtuosa ornamentación en granito estaria presente el deseo manifestado por Gutiérrez Soto de adecuar el edificio a la tradición gallega y ambientarlo en relación con la arquitectura de la ciudad, lo que supone una vuelta atrás, más bien, fruto del momento histórico que de la propia trayectoria del arquitecto. Por otro lado, este cine era la expresión de la pervivencia de la arquitectura que en la ciudad se habia realizado desde principios de siglo: un eclecticismo marcado por matices de diversas corrientes: academicismo francés, modernismo, regionalismo, etc., siempre basado en una construcción en granito y con una profusa decoración en el mismo material.

El nuevo cine, cuya decoración interior corrió a cargo de la casa Arcos de Madrid ${ }^{45}$ debió causar honda admiración y satisfacción entre los vigueses al ver un edificio de estas caracteristicas dedicado al espectáculo más popular del momento. Fue inaugurado en función de gala, la noche del 27 de marzo de 1948, proyectándose la pelicula Botón de Ancla, producida por el vigués Cesáreo González ${ }^{46}$.

\section{CINEMA RADIO}

Frente a la monumentalidad y lenguaje historicista del cine Fraga, presenta el Cinema Radio la arquitectura limpia y desornamentada del lenguaje racionalista, fruto de los intentos renovadores, dentro del contexto local, de Francisco Castro Represas y Pedro Alonso Pérez.

Francisco Castro, nacido en Vigo el 11 de junio de 1905, realiza sus estudios en la Escuela de Arquitectura de Madrid, donde toma contacto

45 FV, 27-IHI-1948.

${ }^{46}$ FV, 28-III-1948. PG, 30-|II-1948. 


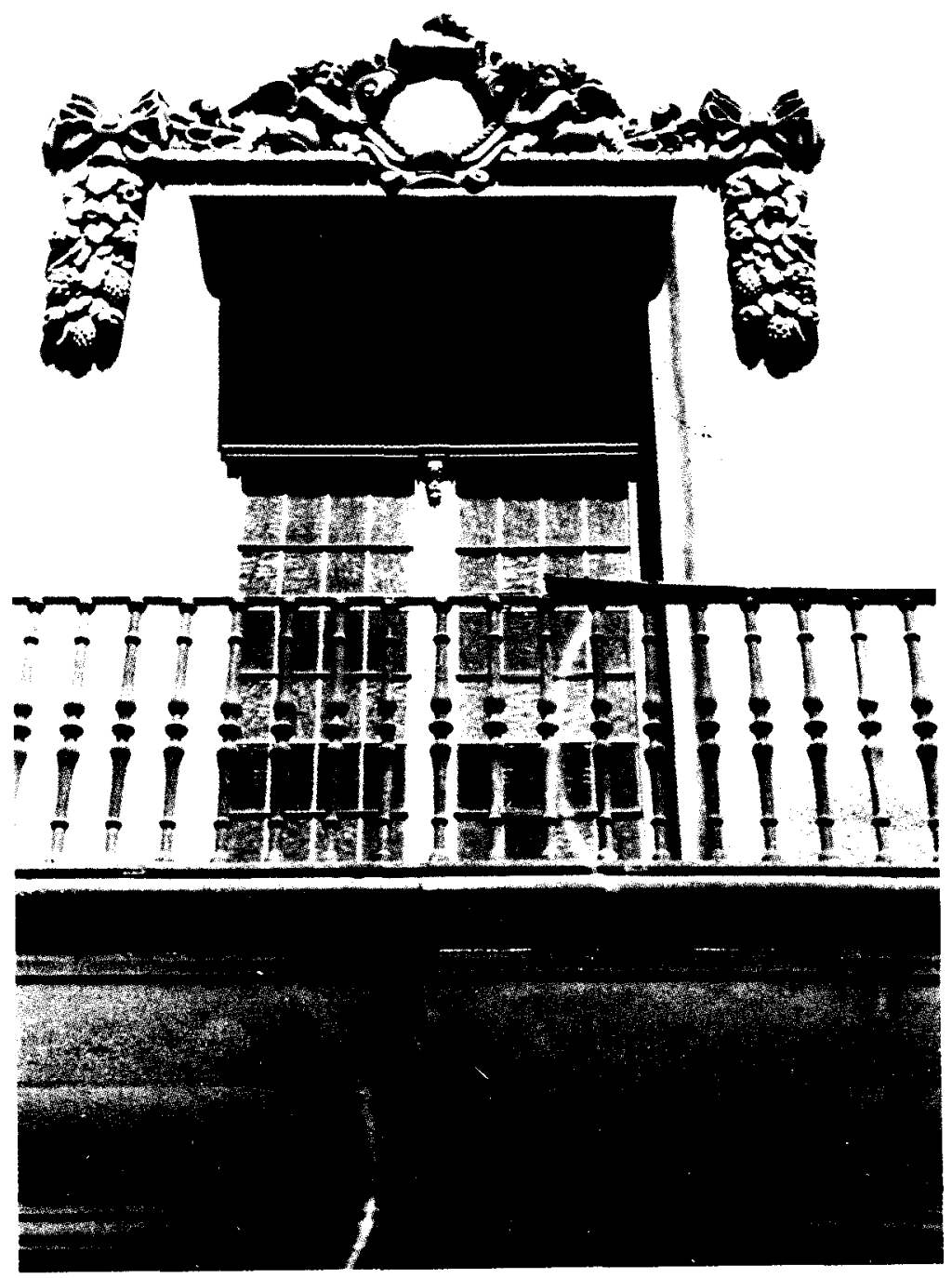

Fig. 14. Cine Fraga, detalle. Gutiérrez Soto 




Fig. 15. Cine Fraga, acceso principal. Gutiérrez Soto 
con las nuevas corrientes arquitectónicas que comienzan a ser impulsadas con fuerza por los integrantes del GATEPAC y ampliamente conocidas a través de las revistas especializadas españolas y extranjeras, mientras que en la Escuela persistía la formación clasicista. Por esta razón, su proyecto de fin de carrera es una sala de exposiciones de lenguaje clasicista ${ }^{47}$. Por otro lado, durante su periodo formativo, estarian presentes las nuevas formas que comenzaban a plasmarse en la arquitectura madrileña de la mano de Fernández Saw, Secundino Zuazo, Carlos Arniches, Martinez Feduchi, etc.

En 1932, una vez terminados su estudios, regresa a su ciudad natal comenzando su labor profesional con gran impulso renovador, introduciendo un nuevo lenguaje que rompia el tradicional y suntuoso eclecticismo local, basado en una rica ornamentación en granito. Su labor en este campo, no suficientemente reconocida, será relevante, sobre todo cuando en la ciudad está presente el tradicionalismo, reflejado también en la aceptación que, en algunos ambientes, mantiene el intento de arquitectura regionalista, representada por los chalés que proyectan Manuel Gómez Román y Antonio Cominges en las zonas residenciales de la ciudad y en parte de la obra gallega del propio Antonio Palacios.

En la introducción de las nuevas corrientes en la ciudad, conservará el carácter propio de la arquitectura local, la preferencia por el granito como material constructivo y expresivo, dando lugar a un racionalismo peculiar y no ortodoxo, en el que está presente la influencia de la arquitectura inspirada en formas aerodinámicas y de barco. Como señala el propio arquitecto, era difícil, en estos momentos, sustraerse el magnifico trabajo de los maestros canteros que trabajaban en la ciudad.

En la etapa anterior a la Guerra Civil deja constancia de su impulso renovador dentro del conjunto de la arquitectura local. En el edificio Sanchón de la calle Policarpo Sanz (fig. 16), suprime toda referencia historicista, presentando un lenguaje limpio en el que solamente están presentes leves detalles decorativos de formas redondeadas. Una mayor limpieza de formas presenta el edificio de viviendas situado en la esquina de las calles Colón y Marqués de Valladares (fig. 17), en el que enlaza las fachadas con una curva mendelsohniana. Este edificio fue concebido para ser recubierto con chapa de granito de diversas tonalidades, optándose definitivamente por recubrirlo con chapa de mármol ante las dificultades económicas. Posteriormente se reformaría la parte inferior de la

47 ACA. La documentación relativa al Cinema Radio y a la obra de ambos arquitectos fue aportada por el propio Francisco Castro. 


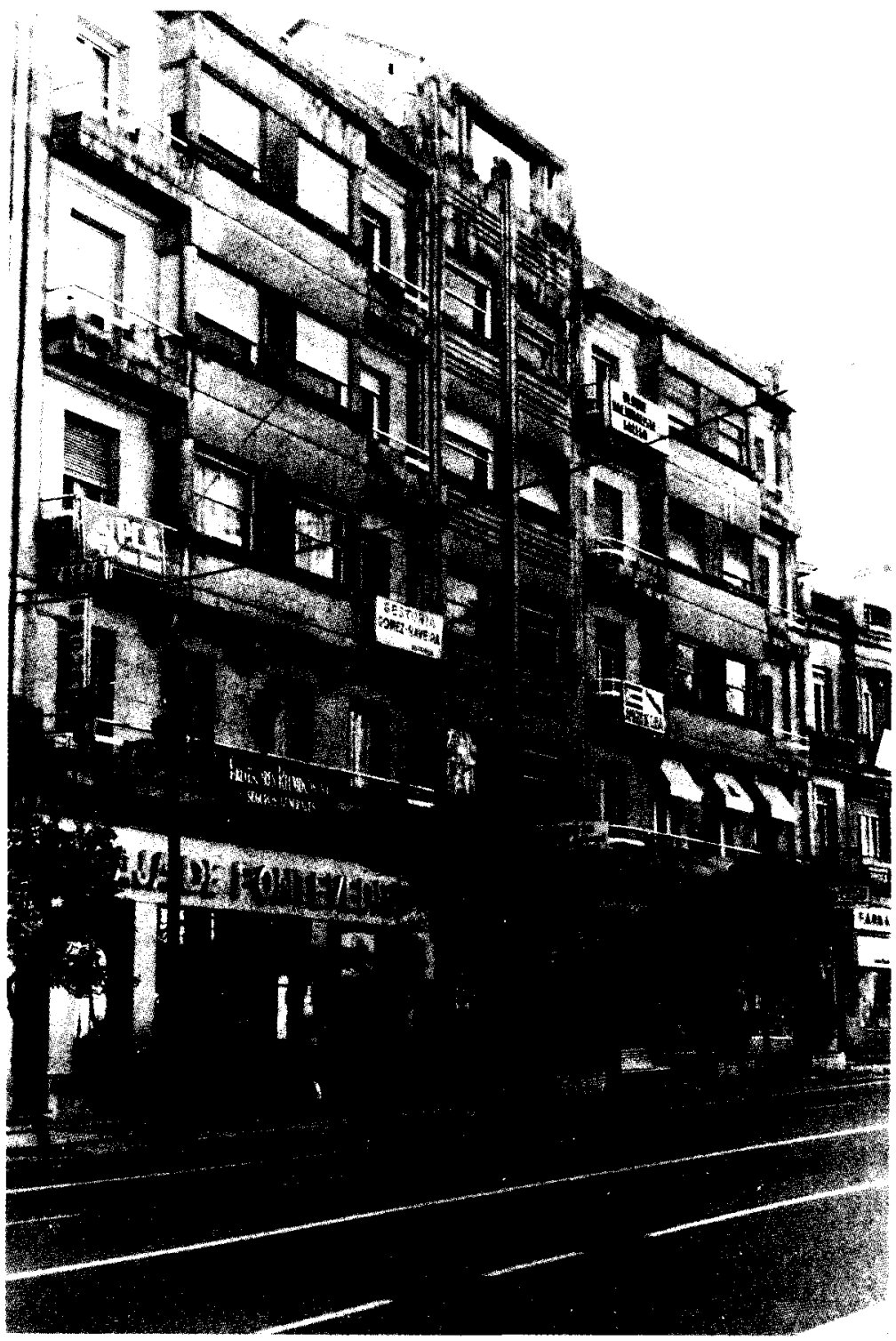

Fig. 16. Edificio Sanchón en calle Policarpo Sanz. Vigo. Francisco Castro Represas 


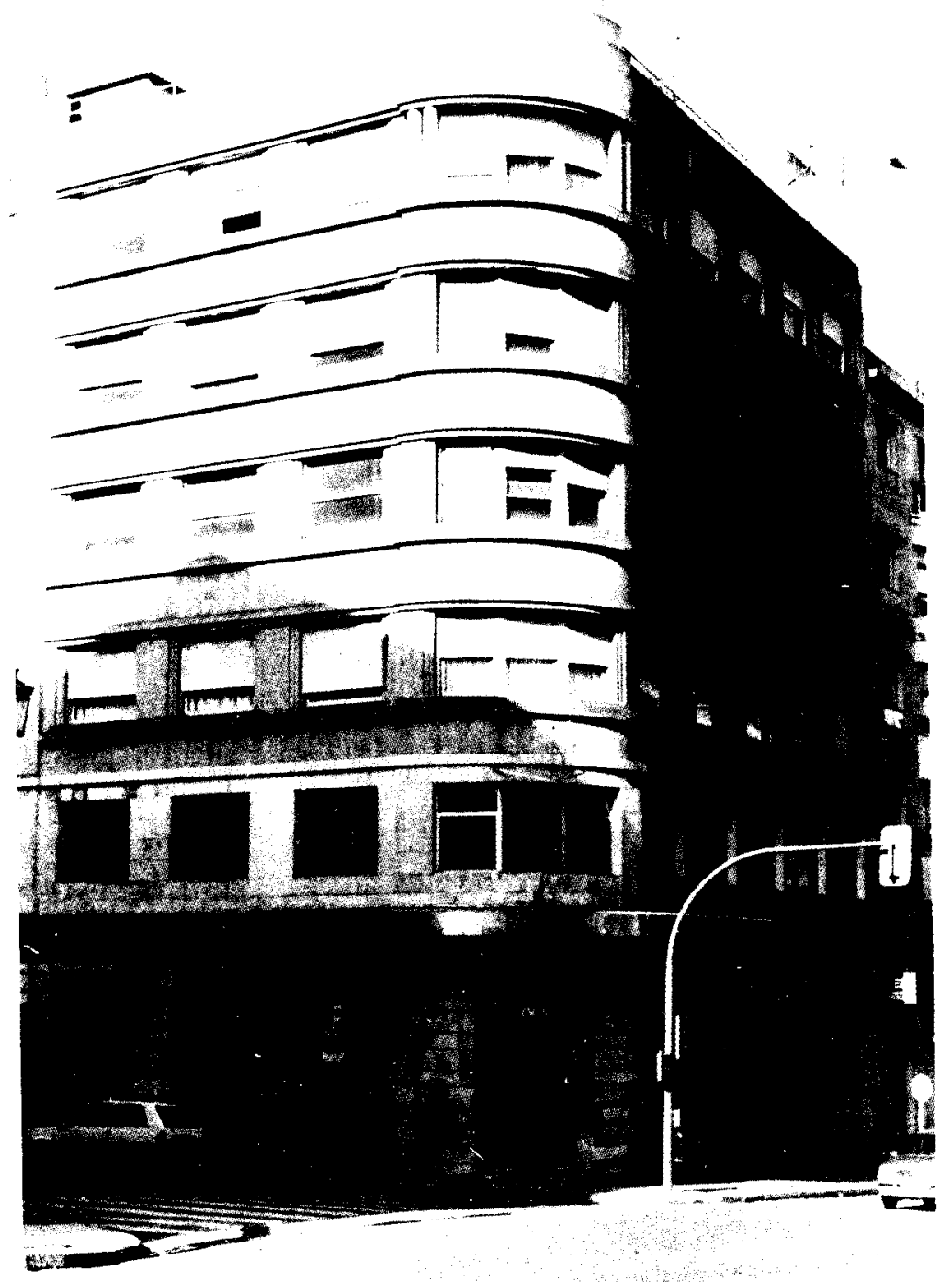

Fig. 17. Edificio de viviendas en calle Marqués de Valladares esquina Colón. Vigo. Francisco Castro Represas 
fachada al instalarse el Banco Exterior, retirándose también los recubrimientos de la parte superior. Dentro del esquema compositivo de algunas de las fachadas, en las que pervive un leve decorativismo, aparece un cuerpo central rehundido que remarca la simetria de la composición, realizándose los enlaces por medio de formas curvas, como sucede en el edificio Curbera de la calle Garcia Borbón, primer edificio de gran altura, en el que combina también granito de diferentes tonalidades. La utilización preferente del granito, presentado limpio y liberado de la carga de repertorios ornamentales se armoniza dentro de la arquitectura de la ciudad, suponiendo un intento logrado de incorporar nuevas formas manteniendo el carácter tradicional de la canteria local, que contrasta fuertemente con la mirada al pasado que realizan los que intentan concretar una arquitectura galleguista. Por otro lado el propio material, concede a estas obras una cierta monumentalidad y solemne armonia, como sucede en el edificio Albo (fig. 18), en la esquina de las calles Gran Vía y Urzaiz que presenta una fachada escalonada en altura, con un lenguaje limpio, marcado por el ordenamiento horizontal que forman las vanos de las ventanas.

La influencia de estos primeros trabajos es grande, ya que progresivamente se irán incorporando a las nuevas corrientes arquitectos que se habían movido dentro del campo del eclecticismo y regionalismo, como es el caso de Cominges y Jenaro de la Fuente Álvarez.

Acabada la Guerra Civil se incorpora al estudio de Francisco Castro su compañero de estudios Pedro Alonso Pérez, nacido en Madrid el 27 de mayo de 1908. En este segundo período son significativos el Club Náutico (fig. 19) y el propio Cinema Radio. Los primeros tanteos para realizar el primero comienzan en el período anterior, sin embargo, la idea no se consolida hasta los primeros años del franquismo. En la dirección de obras participa Pedro Alonso, que aporta un mayor gusto por las molduraciones, presente en el tratamiento de los interiores del club. El exterior, se relaciona con la arquitectura de formas aerodinámicas, presente en muchos clubs de este tipo proyectados en este período, entre los que destaca el de san Sebastián de Aizpurúa y Labayen. Estas formas dinámicas que se incorporan decididamente, en el período anterior, a gasolineras, piscinas, cines, aeropuertos, etc., marcando el cambio de rumbo hacia el racionalismo, dejarán su reflejo en la primera obra de Francisco Castro. El Club Náutico, de grandes proporciones, presenta un lenguaje claro y limpio, de grácil solemnidad, presentando, por su emplazamiento, la novedad de ser el primer edificio en la ciudad que utiliza cimentación de pilotes. 


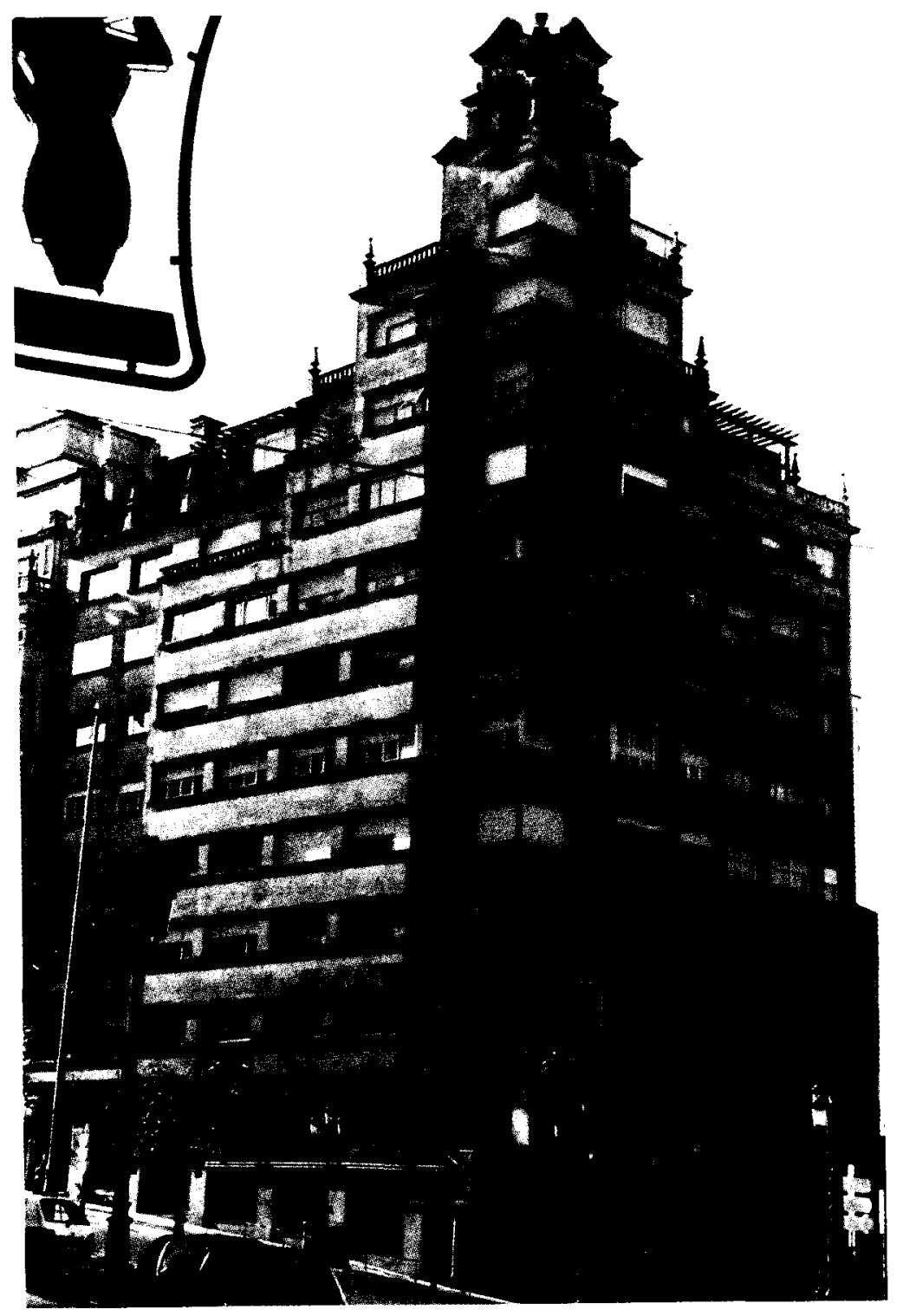

Fig. 18. Edificio Albo en calle Urzaiz esquina Gran Via. Vigo. Francisco Castro Represas 


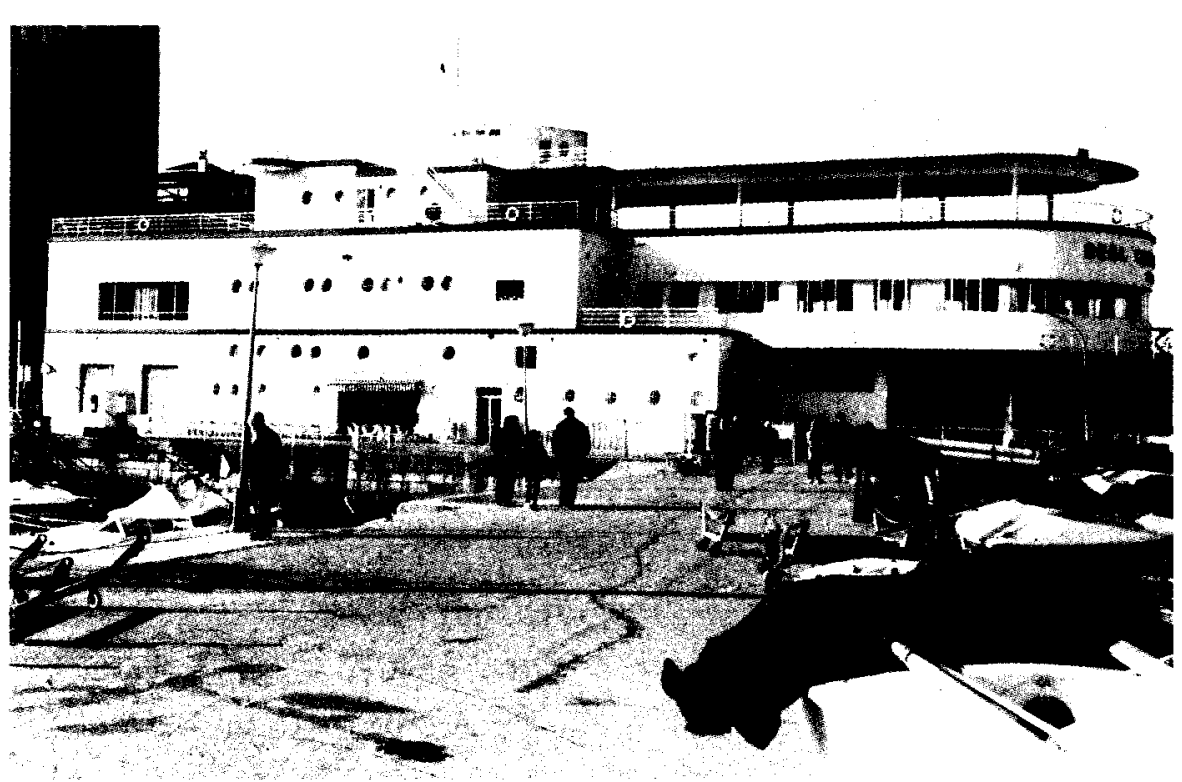

Fig. 19. Club Náutico. Vigo. Francisco Castro y Pedro Alonso

Un lenguaje racionalista más austero y escueto presenta el Cinema Radio (fig. 20), encargado en 1943 por Eugenio González de Haz a Castro y Alonso como reforma de una antigua nave utilizada como cine, situada en el ángulo de las calles Magallanes y María Berdiales.

Según el proyecto original ${ }^{48}$, el cine presentaba una planta cuadrada donde se situaba el patio de butacas, que presentaba un piso curvo, caracteristico de todos los cines de nueva construcción. A este patio se accedia a través de un vestíbulo situado detrás de dos amplias puertas, en el que se disponian las escaleras que conducian al anfiteatro superior (figs. 21 y 22). Destaca en todo el conjunto su funcionalidad, eliminando todos los detalles supérfluos, dejando que el edificio adquiera su propia estética de los propios rasgos arquitectónicos de su construcción. En la composición de la fachada principal se manifiesta el racionalismo del edificio (fig. 23). Castro y Alonso manifiestan en la memoria, que utilizan como elemento decorativo la propia cabina del cine situada encima del anfiteatro, haciendo un pequeño resalto en la fachada de $0,80 \mathrm{~m}$, que se prolonga en toda la altura, desde el hueco de entrada, por encima de la marquesina. En esta fachada se vuelven acusar rasgos propios del fun-

\footnotetext{
${ }^{48}$ ACA. Memoria y planos del Cinema Radio. Año 1943.
} 


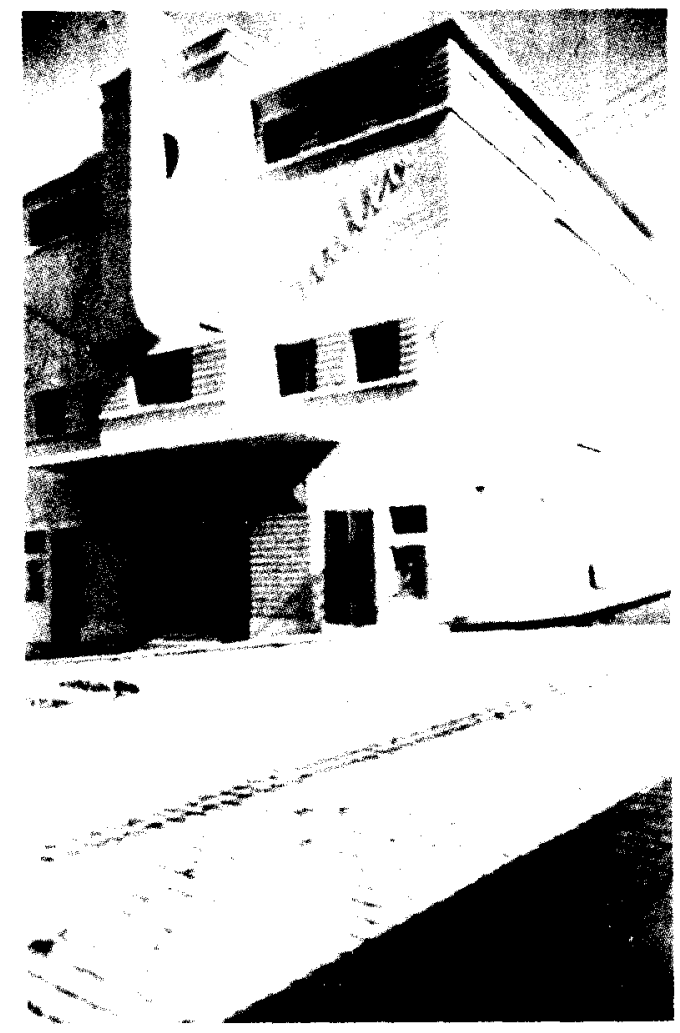

Fig. 20. Cinema Radio. Francisco Castro y Pedro Alonso

cionamiento del cine, ya que forman parte de su composición, los huecos de ventilación, del vestíbulo y del entresuelo que conduce al anfiteatro. En la fachada lateral (fig. 24), más fria y desnuda, el elemento de composición son las puertas de salida exterior, prolongadas con unos ligerisimos recercados. En el interior la decoración es escueta y de formas curvas.

En la elección del lenguaje plástico de edificio hay una plena consciencia de manifestar el carácter funcional de edificio. En la memoria del proyecto los arquitectos afirman:

"La decoración, tanto de salas como de las restantes dependencias es funcional, acusando la estructura y abovedando los techos de los vestíbulos, a fin de obtener una mayor altura libre debajo del entramado del anfiteatro. 


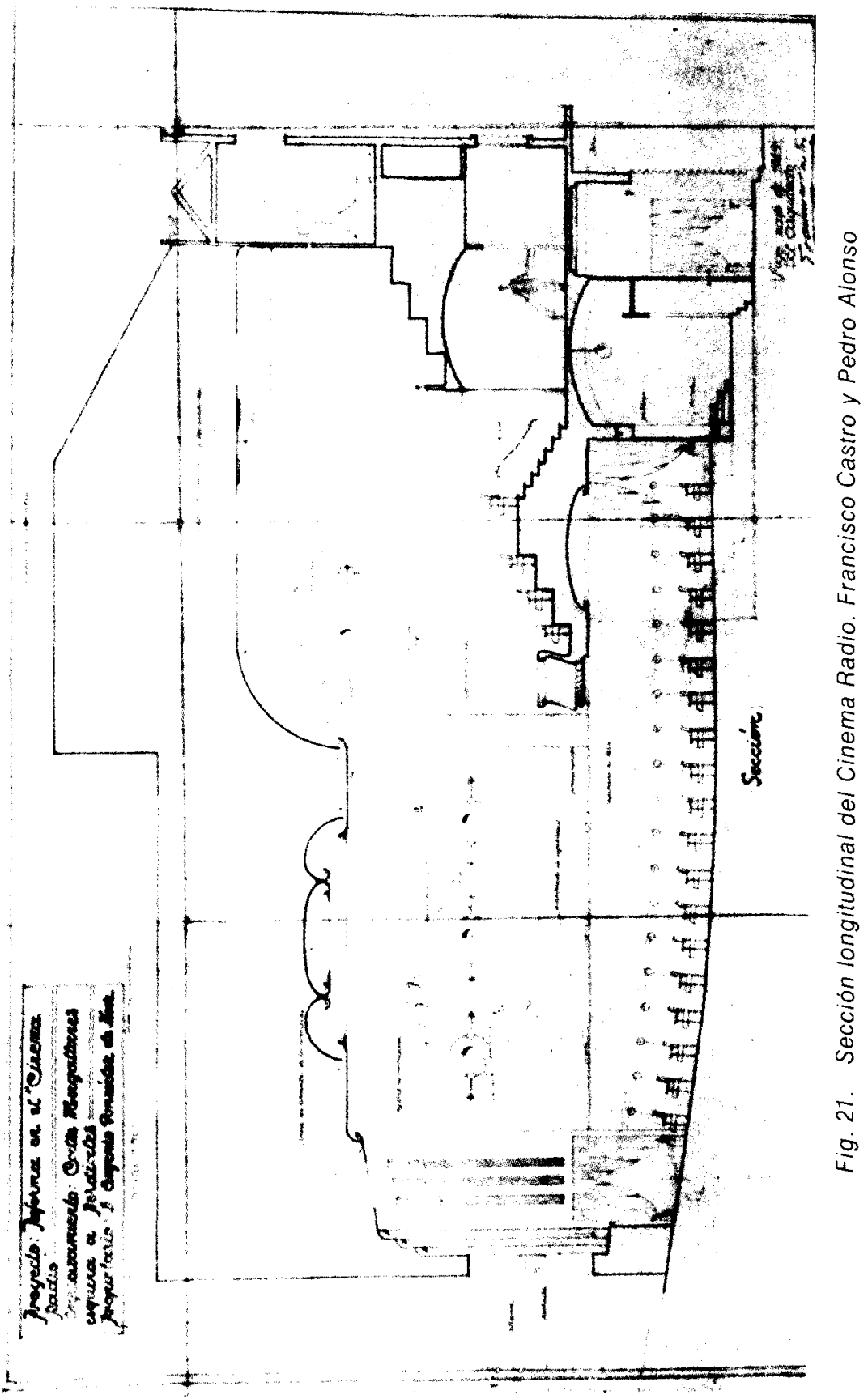




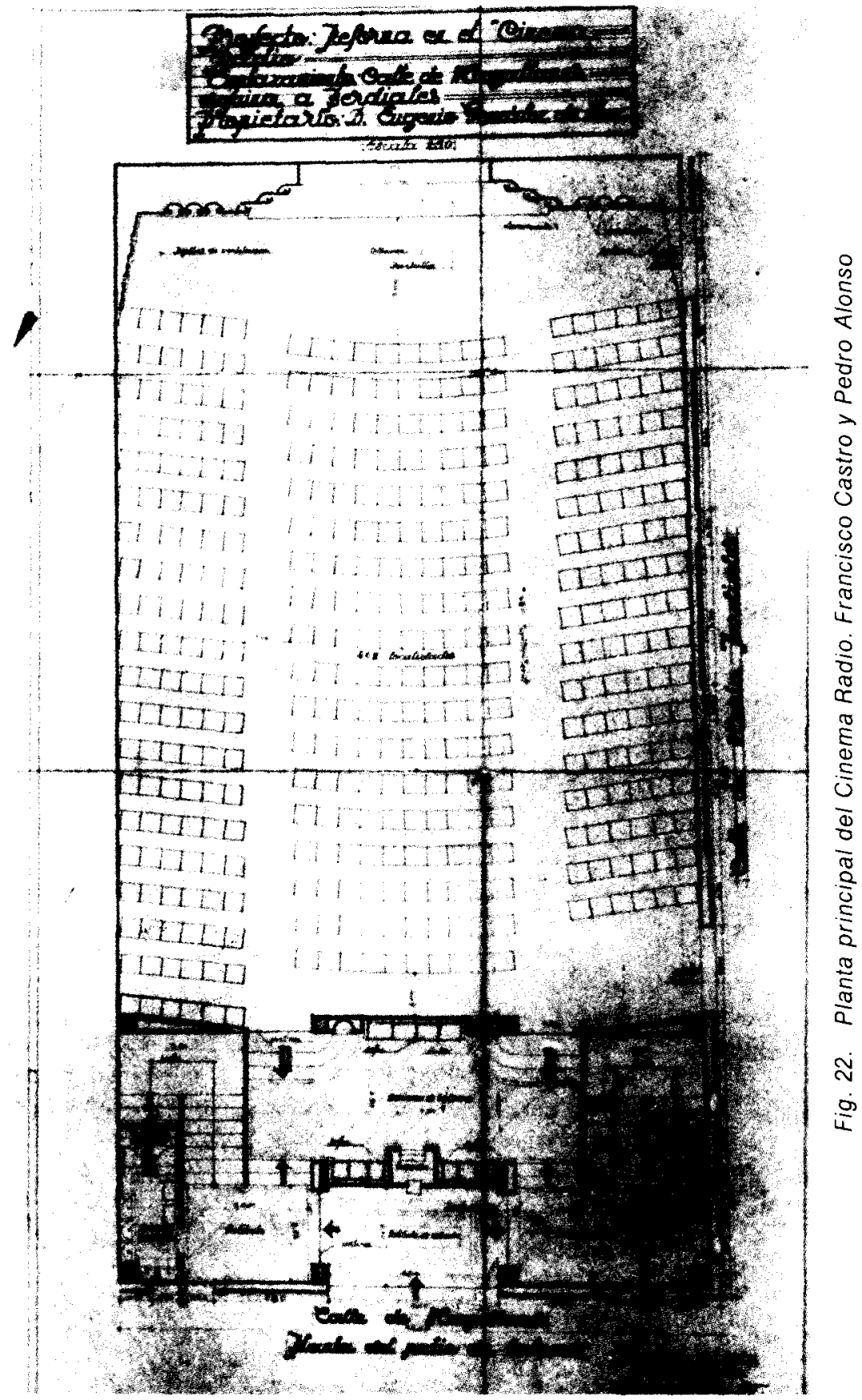




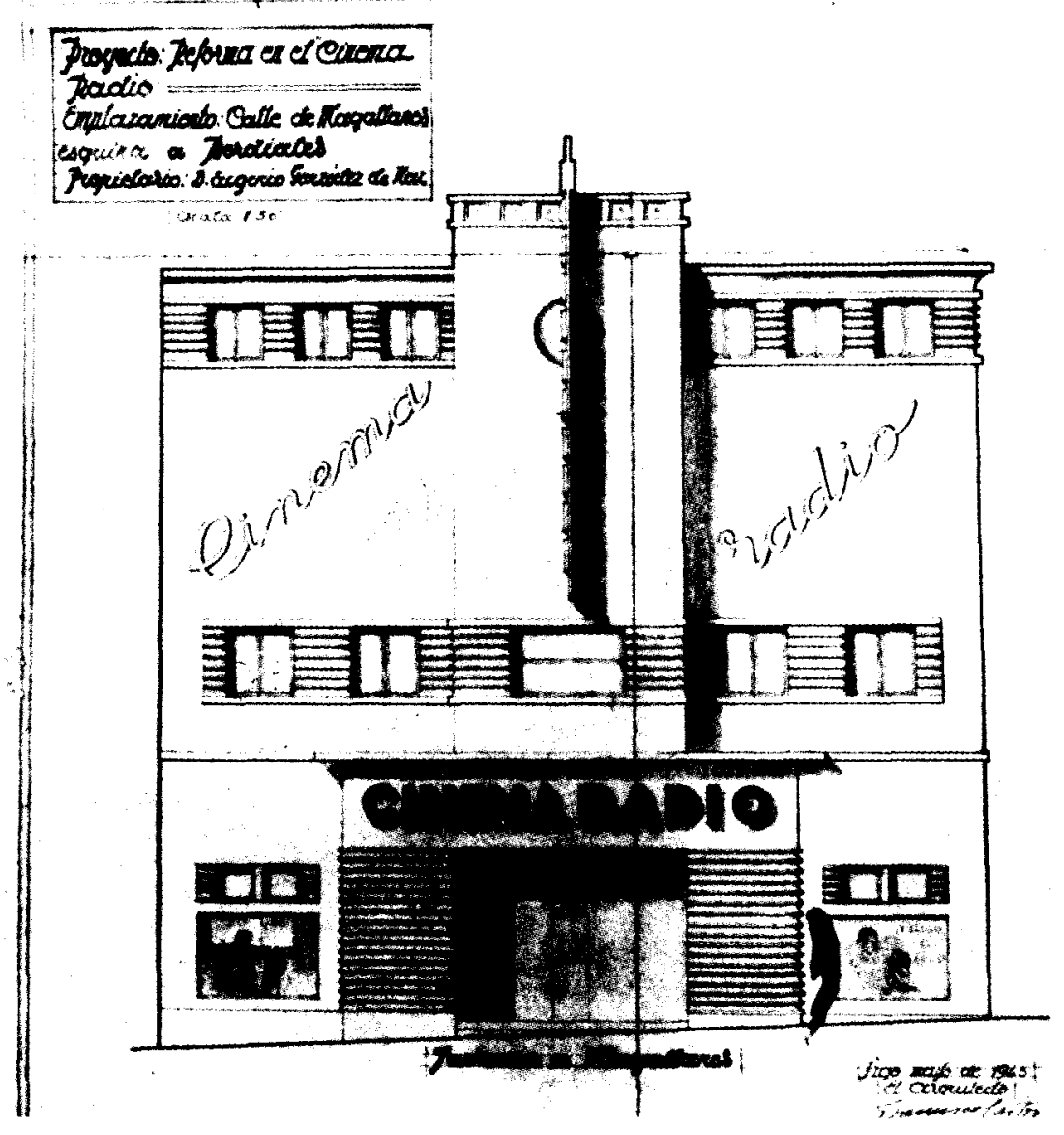

Fig. 23. Alzado de la fachada principal del Cinema Radio. Francisco Castro y Pedro Alonso

"El aspecto grato de estas dependencias se completará con la colocación de espejos, divanes y flores, todo ello entonado con una pintura al temple en los paramentos a base de colores de tono claro y alegre.

"Respecto al exterior, no hay que olvidar que las fachadas de esta clase de edificios, son verdaderos carteles de propaganda, acusando por su composición el destino del edificio.

"A este concepto, responden en la fachada principal, la marquesina, torreta de la cabina, colocación de carteleras y huecos, para dar un movimiento a la fachada que, juntamente con los colores llamativos de la propaganda de las peliculas y los letreros luminosos harán que se fijen la atención en los programas que se ofrezcan». 


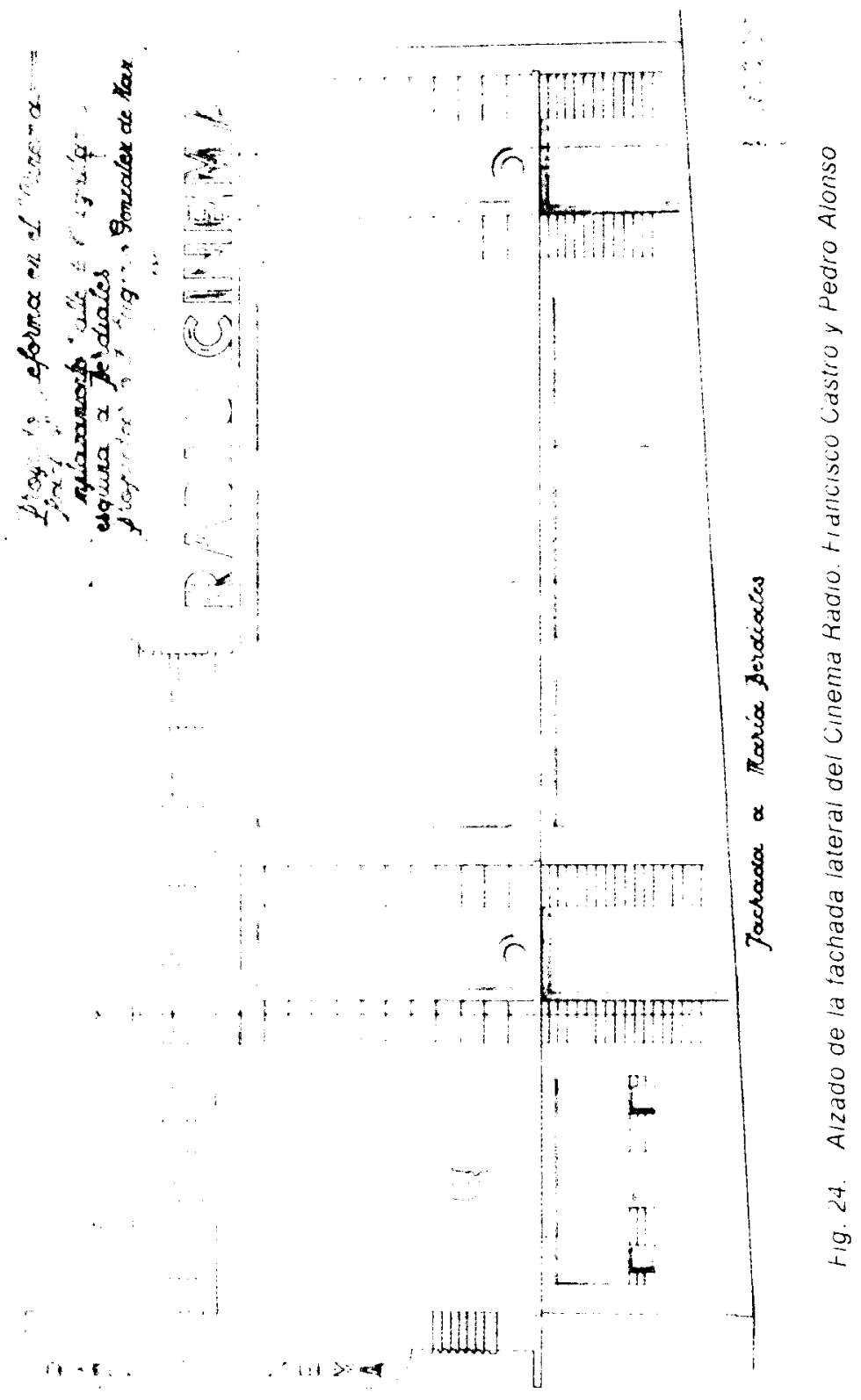


Este cine es un ejemplo de la arquitectura que Francisco Castro y Pedro Alonso habian comenzado a introducir en la ciudad, rompiendo el excesivo énfasis decorativo característico de la arquitectura realizada en la ciudad de Vigo desde principios de siglo, sirviendo de puente para que la generación posterior implante definitivamente la arquitectura del movimiento moderno. 